\title{
Behaviour and fate of urban particles in coastal waters: Settling rate, size distribution and metals contamination characterization
}

\author{
B. Oursel ${ }^{a, *}$, C. Garnier ${ }^{a}$, I. Pairaud ${ }^{b}$, D. Omanovićc ${ }^{c}$, G. Durrieu ${ }^{a}$, A.D. Syakti ${ }^{d, e}$, C. Le Poupon ${ }^{a}$, \\ B. Thouvenin ${ }^{\dagger}$, Y. Lucas ${ }^{a}$
}

${ }^{1}$ Université de Toulon, PROTEE, EA 3819, 83957 La Garde, France

2 IFREMER, Centre de Méditerranée, Laboratoire Environnement Ressources Provence-Azur-Corse, BP 330 , Zone Portuaire de Brégaillon, 83507 La Seyne-sur-Mer, France

${ }^{3}$ Ruđer Bošković Institute, Center for Marine and Environmental Research, PO Box 180, 10002 Zagreb, Croatia

${ }^{4}$ Aix Marseille Université, LCE - FRE 3416, équipe MPO, Europôle de l'Arbois, BP 80, 13545 Aix-en-Provence Cedex 4, France

${ }_{5}$ Fisheries and Marine Science Department, Faculty of Sciences and Techniques, University of Jenderal Soedirman, Jl. HR. Boenyamin 708-Purwokerto, Indonesia

${ }^{6}$ IFREMER, Centre de Brest, DYNECO, DYNECO/PHYSED, BP 70, 29280 Plouzané, France

*: Corresponding author : B. Oursel, email address : oursel@univ-tIn.fr

\begin{abstract}
:
The evaluation of contaminant net fluxes from the coast to the open sea requires the study of terrigeneous particles behaviour and fate. We studied the particles issued from two small coastal rivers whose waters are mixed with treated wastewater (TWW) coming from the Marseille wastewater treatment plant (WWTP) just before discharge to the Mediterranean Sea. An experimental device was developed and used to investigate particles settling rates, size distribution and metallic contamination when mixing with seawater. The particles were sampled in flood deposits of rivers and outlets during rainy periods and in the outlet water during dry periods. The flood deposits were mainly composed of 50-200 $\mu \mathrm{m}$-sized particles, higher metals content being observed in the finest fractions. Dry period particles showed the stronger influence of wastewater inputs. $\mathrm{Al}, \mathrm{Ca}, \mathrm{Cs}, \mathrm{Li}, \mathrm{Rb}, \mathrm{Ti}$, and $\mathrm{Tl}$ were mainly of terrigeneous origin, whereas $\mathrm{Ag}, \mathrm{Ba}, \mathrm{Cd}, \mathrm{Cr}, \mathrm{Cu}, \mathrm{Hg}, \mathrm{Mg}, \mathrm{Mo}, \mathrm{Ni}, \mathrm{Pb}, \mathrm{POC}, \mathrm{Sb}, \mathrm{Sn}$ and $\mathrm{Zn}$ were of anthropogenic origin, issued from non-treated sewage, TWW or industrial waste. In seafloor sediments, all metals exhibited a continuous increase of concentration from the outlet to, at least, $800 \mathrm{~m}$ offshore. Implementation of settling particles characteristics in a 3D hydrodynamic and sediment transport model reproduced well the observed deposition of polluted particles in the coastal zone and indicated a non-negligible offshore export of the finest particles and their accompanying pollutants.
\end{abstract}

\section{Highlights:}

- Chemical and physical characterization of river particles issued from a large urban agglomeration. Origin of metals in urban/river particles. Modelling of the behaviour and fate of urban particles in coastal zone. Significant metal contamination of sediments in coastal zone. Desorption processes control metal dissolved/particulate fractionation.

Keywords: particles contamination ; urban rivers ; coastal zone ; TWW ; hydro sedimentation modelling

1. Introduction

Trace metals are natural constituents of crustal materials. Some of them are essential to the biota, but all have the potential to be biologically toxic if their concentration exceeds certain levels. A wide range of trace metals may be generated throughout human activities, then discharged in rivers by soil erosion processes (depending on the nature of the watershed), throughout wastewaters (treated or not), throughout industrial activities (Azimi et al., 2005) and throughout agriculture (Waeles et al., 2007). Trace metals may be brought by rivers to the coastal area by continuous, diffuse inputs or during flood events, then can accumulate in 
marine sediments. Their input in the water column and in sediments may be a threat to the quality of the coastal area (Rocha et al., 2011; Weber et al., 2009). Gobeil et al. (2005) studying the Montreal (Canada) WWTP discharge in a large river, the St. Lawrence, have shown that the contribution of the treated wastewater (TWW) was not significant compared to the river metal budget, except for Ag. On the contrary, Oursel et al. (2013) have studied the Marseille (France) WWTP discharge in a small river and showed that, during baseflow periods, the river signature was hidden by the TWW input for most elements or compounds. This difference is due to the larger proportion of TWW discharge in the river stream in the case of Marseille with regard to Montreal (50\% versus 1\%, respectively). During flood events, significant amounts of trace metals are rapidly brought to surface aquatic system through runoff processes (Di Leonardo et al., 2009; Elbaz-Poulichet et al., 2001; Nicolau et al., 2012; Rocha et al., 2011; Weber et al., 2009). In order to evaluate the impact of such inputs to coastal zones, previous studies have quantified contaminant fluxes at river mouth (Michel et al., 2000; Nicolau et al., 2012; Ollivier et al., 2011; Statham et al., 1999), whereas others have focused on the contaminants fate in the mixing zone, identifying sorptiondesorption processes or changes in chemical speciation (Dassenakis et al., 1997; ElbazPoulichet et al., 1996; Millward and Liu, 2003; Waeles et al., 2005; Zwolsman et al., 1997). It is therefore necessary to study the fate of particulate pollutants in the coastal zone (Millward et al., 1999), such studies requiring specific experiments.

The settling velocity of river particles in and beneath the river plume is difficult to measure because the fine material can flocculate rapidly in seawater. Indeed, during freshwater/seawater mixing the suspended matter are subjected to important changes in physicochemical properties of the water and their behaviour will depend on their nature, concentration and organic matter content (Fugate and Chant, 2006; Thill et al., 2001). At local scale, the extension and direction of the dilution plume defines where particles settle or are exported depending on the river flow, tide, wind, currents and the morphology of the study area (Alliot et al., 2003; Cugier and Le Hir, 2002; Naudin et al., 1997; Pairaud et al., 2011). Once in the water column, metals can undergo quick desorption or reversely adsorption onto particles. Particles settle directly or after flocculation and accumulate in sediments, which therefore act as a metal sink: the quantification of metal content in surface sediments is consequently a first step to assess the degree of pollution of a marine environment (Bay et al., 2003; Tessier et al., 2011). The grain size is one of the main factors that govern metals contamination in the particulate fraction, as the finest particles contain minerals (e.g. clays, oxides, sulfides, ...) and particulate organic matter having strong affinity with metals. There 
is generally a marked inverse correlation between grain size and metal content in the sediment (Forstner and Wittmann., 1979; Forstner and Patchineelum., 1980). It is therefore critical to quantify the particles size distribution and to assess their settling velocity in the mixing zone. In the last four decades, numerous techniques have been developed for in situ measurement of particles size and settling velocities (Eisma et al., 1996). The Owen tube was for instance used since1971 to measure the settling velocity distribution of the suspended particulate matter (SPM). It consists in a tube sampler opened at both ends, which is lowered horizontally into the water, closed by trigger at the required depth then rotated vertically (Dyer et al., 1996). The Quisset tube, adapted from the Owen tube, has been developed to determine the settling velocity of particles in the Elbe estuary (Jones and Jago, 1996).These techniques, however, are poorly suited to a shallow plume that is not channelled through an estuary and can move quickly after wind and current changes and their use was, to our knowledge, not associated to the determination of chemical properties in relation with particle size.

Moreover, only few studies focused on the Mediterranean area despite its high population density and its climate specificities. Marseille is an example of large Mediterranean city, where the city WWTP effluents are mixed with small rivers before being rapidly discharged at sea, without passing through an estuary (Oursel et al., 2013).

In this context, through the adaptation of an instrumental laboratory device to separate particles accordingly to their settling velocity in seawater followed by the analysis of the elemental (minor, major and trace) content of each particle size fraction, the purposes of this study were (1) to investigate the physical and chemical characteristics of river/urban particles discharged to the coastal environment, (2) to relate the obtained results with the surface sediment quality in the coastal area and finally (3) to implement a 3D hydrodynamic (Pairaud et al., 2011) and sediment transport model (Verney et al., 2013) within the area to investigate the role of heavy rainfall events on the fate of contaminated particles.

\section{Material and methods}

\subsection{Study site}

The Huveaune River extends over $48.4 \mathrm{~km}$ long and runs through a watershed with an area of $523 \mathrm{~km}^{2}$ which consists in karstic formation (60\%) and detrital sediments. Land-use in the downstream part of the watershed is urban and industrial. The Jarret River extends over 21 $\mathrm{km}$ with a $102 \mathrm{~km}^{2}$ watershed mainly urban and industrial. 
In dry period, these two rivers merge in Marseille; the resulting water is mixed with the Marseille City WWTPs effluent, and then channelled by the Outlet 2 (Out2) to the sea at the Calanque of Cortiou (Fig. 1 and Fig. SI-4.1). This treatment plant, one of the largest in Europe (1.7 $10^{6}$ inhabitant eq.), uses both physical and biological treatment processes. During dry periods ( 300 days), around 100 and $80 \mathrm{Mm}^{3} \mathrm{y}^{-1}$ of TWW and river water, respectively, are discharged to the sea (Le Masson, 1997). Oursel et al. (2013) have evaluated the annual global SPM discharge to be around $3900 \mathrm{t}$, whose $840 \mathrm{t}$ coming from rivers, highlighting the main contribution of the TWW in such conditions. During flood events, the Huveaune and Jarret river flows can overpass 60 and $16 \mathrm{~m}^{3} \mathrm{~s}^{-1}$, respectively. As the maximal outlet discharge capacity cannot overpass $30 \mathrm{~m}^{3} \mathrm{~s}^{-1}$, a significant part of rivers waters is channelled through the Huveaune former bed to the Prado's beach (Fig.1) during extreme events, i.e. when rainfall overpass $\sim 40 \mathrm{~mm} \mathrm{~h}^{-1}$. During rainy periods, around 4.1 and $9 \mathrm{Mm}^{3} \mathrm{y}^{-1}$ of TWW and rivers waters, respectively, are discharged to the sea. Le Masson (1997) has evaluated the corresponding SPM discharge to 6500 t, 94\% coming from rivers. On average, during flood events, $90 \%$ of Huveaune and Jarret waters (and SPM) are channelled through the outlet and only $10 \%$ are deviated through the Huveaune former bed. Additionally, discharge of untreated wastewater brought to the coastal zone between 456 and $1450 \mathrm{t} \mathrm{y}^{-1}$ of SPM, during the period 2001-2007 (Jany et al., 2012).

Statistics on the 01/01/2009 to 31/08/2011 studied period (Météo-France) showed an average of $609 \mathrm{~mm} \mathrm{y}^{-1}$ of rain distributed as follow: 304, 41, 12, 5and $3 \mathrm{~d} \mathrm{y}^{-1}$ where rain was $<1,1-10,10-20,20-40$ and $>40 \mathrm{~mm} \mathrm{~d}^{-1}$, respectively, which are typical values for a Mediterranean coastal area.

\subsection{Sampling and sample conditioning}

Two types of samples were considered: (1) flood deposits sampled after a rain with the aim of characterizing most of the particles discharged to the sea during flood events and (2) suspended matter collected using a sediment sampler placed in the river flow (Phillips et al., 2000) in order to characterize the particles brought to the sea during base-flow periods.

\subsubsection{Rainy periods sampling}

In order to characterise particle inputs to the Calanque of Cortiou, flood deposits were sampled after a rainy event on the 11/05/2009 at Outlet 1 (FDOut1) and on the 14/04/2011 at Outlet 2 (FDOut2). Outlet 1 is only active when the WWTP is by-passed (Fig. SI-4.1) due to 
an overflow of sewage/rain waters mixture due to the fact that the old Marseille centre has a non-separated sewage network which collects both wastewaters and runoff. The FDOut1 sample is thus likely to contain non-treated sewage particles, as also occurs in many southern Mediterranean coastal cities. In order to characterise particle inputs upstream the WWTP, flood deposits were sampled on 14/04/2011 after a rainy event in the Huveaune (FDHuv) and Jarret rivers (FDJar). The flood deposits were sampled manually, frozen at $-18^{\circ} \mathrm{C}$ in the laboratory, subsequently freeze-dried and 2-mm sieved.

\subsubsection{Base-flow period sampling}

Suspended particles during dry period corresponding to the river baseflow mixed with TWW were sampled in Outlet 2 (SPOut2) using a sediment sampler built by IFREMER according to Phillips et al. (2000). This $1 \mathrm{~m}$ long inox tube was installed in Outlet 2. Phillips et al. (2000) have shown that such device collects $\sim 71 \%$ of the total river particles, taking into account that the faster the river flow, the more fine particles pass throughout the system. After 1 month, the sampler water and SPM were collected in 10 L HDPE (high density polyethylene) bottles. Bottles were placed in the fridge at $+4^{\circ} \mathrm{C}$ during one day for particles sedimentation. Then supernatant water was siphoned using a pump and wet particles were stored in $120 \mathrm{~mL}$ HDPE bottles, frozen at $-18^{\circ} \mathrm{C}$ and subsequently freeze-dried. The maximal diameter of collected particles was $4 \mathrm{~mm}$, corresponding to the diameter of the inlet hole.

In this study, the SPOut2 sample used corresponds to the sampling period from 11/04/2011 to 11/05/2011. During this month, only $30 \mathrm{~mm}$ of cumulative rainfall (MétéoFrance) were brought to rivers, which represented around $2 \%$ and $12 \%$ of the month total water and SPM discharge, respectively, accordingly to the recorded outlet flow and average SPM concentration during dry and rainy periods (data not shown). In such conditions, the SPOut2 sample can be considered as mainly representative of dry period particle inputs.

\subsubsection{Sediment sampling}

Twelve surface sediments were sampled along a transect from the coast to the open sea at the Calanque of Cortiou (Fig.1) by divers. Sampled sediments were treated using the same protocol developed previously for flood deposits.

\subsection{Settling rates experiment}


The experimental device was composed by a vertical Plexiglas tube $(1 \mathrm{~m}$ long and $10 \mathrm{~cm}$ diameter), open on the top and equipped with a valve on the bottom to collect water samples. The tube was filled with $7 \mathrm{~L}$ of "clean" seawater sampled at $2 \mathrm{~km}$ offshore and $4 \mathrm{~m}$ depth (Oursel et al., 2013) and equilibrated during one day to obtain a homogeneous temperature of the water column $\left(20^{\circ} \mathrm{C}\right)$. During flood conditions, SPM can exceed $1 \mathrm{~g} \mathrm{~L}^{-1}$ in tributaries (Jany et al., 2012). Accordingly, the experiments were performed using $7 \mathrm{~g}$ of dried particles (flood deposit or dry period particles) pre-wetted with few $\mathrm{mL}$ of milliQ water (Millipore 18.2 $\mathrm{M} \Omega$ ). Such mass also allowed to collect enough material to perform chemical analysis. After one day of wetting, particles were injected on the top of the system and the bottom $500 \mathrm{~mL}$ were successively sampled at 14 times (in log scale) ranging from $30 \mathrm{~s}$ to 5 days, so covering a large domain of settling rates and particles diameters (Dyer et al., 1996). The 14 samples were immediately filtered (see part 2.4) and particles which had remained on the walls of the tube were collected in a $15^{\text {th }}$ class corresponding to the fraction which cannot settle in the defined conditions.

Accordingly, settling velocity and particle diameter were calculated for the 14 classes (supplementary information SI-1).

\subsection{Filtration protocols and filters treatment}

A part of the collecting samples was filtered through $25 \mathrm{~mm}$ glass filters (Whatman GFF, $0.7 \mu \mathrm{m}$ ) for particulate organic carbon (POC) analysis. The filter treatment protocol for POC analysis is described in Oursel et al. (2013).

The remaining water was then filtered through $47 \mathrm{~mm}$ cellulose nitrate filters (Sartorius, $0.45 \mu \mathrm{m})$ for particulate elements analysis. Half of each filter was used to quantify major/minor/trace elements after microwave digestion (AntonPaar Multiwave 3000) in aqua regia (trace metal grade acids, Fisher Scientific) accordingly to a procedure previously validated (Tessier et al., 2011). The second half of the filter was used to quantify particulate mercury.

\subsection{Mineralogical characterization}

Mineralogical identification of dried sieved $(2 \mathrm{~mm})$ samples was done by X-ray diffraction (XRD) spectroscopy with $\mathrm{Cu} \mathrm{K} \alpha$ radiation (Phillips, PW1200) on powder samples 
finely crushed in a tungsten carbide mill. Because of the low quantity of particles collected in the tube during dry period, the XRD analyse was not realized on SPOut2 sample.

\subsection{Batch experiments}

As dissolved metals were not analysed from the settling rate experiment (due to the nonhomogeneity of the water column inside the settling tube), an additional batch experiments were undertaken to study metal release from particles in seawater. Flood deposits and baseflow period particles samples were mixed to seawater in FEP bottles (SPM $=1 \mathrm{~g} \mathrm{~L}^{-1}$ ). FEP bottles were placed on head-over-head agitation system (Reax 20, Heidolph) and aliquots were sampled at $15 \mathrm{~min}, 1,6,24 \mathrm{~h}$ and 5 days of mixing time using pre-cleaned syringe, then filtered through pre-cleaned $0.22 \mu \mathrm{m}$ on-line filters (Sartorius). A first aliquot of filtrate (dissolved fraction) was stored in 60mL FEP bottles, acidified with $60 \mu \mathrm{L} \mathrm{HNO}$ (supra pure $65 \%$, Merck) and digested $2 \mathrm{~h}$ under UV-irradiation (Metrohm 705, $500 \mathrm{~W}$ ) for further analysis of total dissolved metal concentrations (Louis et al., 2009). A second aliquot of filtrate was stored in $24 \mathrm{~mL}$ glass tube (Wheaton, equipped with Teflon/silicone septum) precalcinated $4 \mathrm{~h}$ at $450^{\circ} \mathrm{C}$, azidified with $25 \mu \mathrm{L} 1 \mathrm{M} \mathrm{NaN}_{3}\left(\mathrm{NaN}_{3}>99 \%\right.$, Aldrich) and kept at $4^{\circ} \mathrm{C}$ for further analysis of dissolved organic carbon (DOC).

\subsection{Sample chemical analysis}

\subsubsection{Particulate phase characterization}

\subsubsection{Particulate carbon forms}

Total carbon (TC) contents were quantified from flood deposits, suspended particles and sediments using a TOC- $\mathrm{V}_{\mathrm{CSH}}$ analyzer (Shimadzu), coupled with a SSM-5000A module. The total and organic carbon contents were determined using the high-temperature $\left(900^{\circ} \mathrm{C}\right)$ catalytic oxidation method with $\mathrm{CO}_{2}$ IR detection (Ammann et al., 2000; Callahan et al., 2004), calibrated using glucose (Analytical reagent grade, Fisher Scientific) with an accuracy of $0.1 \mathrm{mgC}$. For POC analyse, GFF filters were dried to constant weight at $60{ }^{\circ} \mathrm{C}$, and then exposed to $\mathrm{HCl}$ fumes for $4 \mathrm{~h}$ to remove all the inorganic carbon (Lorrain et al., 2003).

Particulate inorganic carbon (PIC) contents were quantified from flood deposits, suspended particles and sediments using the same analytical equipment after addition of $\mathrm{H}_{3} \mathrm{PO}_{4}$ (Analytical Reagent grade $85 \%$, Fisher Scientific) at $200^{\circ} \mathrm{C}$ followed by $\mathrm{CO}_{2} \mathrm{IR}$ 
detection, calibrated using $\mathrm{NaHCO}_{3} / \mathrm{Na}_{2} \mathrm{CO}_{3}$ (Shimadzu) with an accuracy of $0.1 \mathrm{mgC}$. Then,

POC content was calculated by difference between total and inorganic carbon contents.

\subsubsection{Major elements}

Major elements $(\mathrm{Ca}, \mathrm{K}, \mathrm{Mg}$ and $\mathrm{Na}$ ) were analysed by a flame atomic absorption spectroscopy (VARIAN SpectrAA 800). The instrument was calibrated using standard solutions and flame was supplied with a mixing of acetylene (99.99\%) and air. Major elements analysis was validated using certified reference material (MISSIPPI-03, Canada); obtained values remained within the certified limits.

\subsubsection{Minor and trace elements analysis}

Particulate elements (Ag, Al, As, Ba, Be, Bi, Cd, Co, Cr, Cs, Cu, Fe, $\mathrm{Li}, \mathrm{Mn}, \mathrm{Mo}, \mathrm{Ni}, \mathrm{Pb}$, $\mathrm{Rb}, \mathrm{Sb}, \mathrm{Sn}, \mathrm{Sr}, \mathrm{Ti}, \mathrm{Tl}, \mathrm{U}, \mathrm{V}$ and $\mathrm{Zn}$ ) were quantified from the acid-digested filters by High Resolution Inductively Coupled Plasma Mass Spectrometry (HR ICP-MS Element 2, Thermo Finnigan). The instrument was calibrated using standard solutions and an In was added as internal standard in each sample (Lenoble et al., 2013). Quality control of HR ICP-MS measurements was checked by the determination of elements concentration on Certified Reference Material (SLRS-4 river water, LGC6187 river sediment, National Research Council Canada). All results presented good agreement with the certified data. Results obtained for LGC6187 (triplicate) are provided in Table SI-2, showing that the values obtained for most of the studied elements fall in $90-110 \%$ of yield an/or in the required range of certified contents at the exception of $\mathrm{V}$ having slightly higher value.

\subsubsection{Particulate mercury}

Mercury analysis was carried out using an automatic AMA-254 (ALTEC) analyzer. Filters were divided in few small pieces placed in a nickel nacelle and introduced into the system. The principle of the method is described in Heimbürger et al. (2012) and the detection limit of the method was $0.007 \mu \mathrm{g} \mathrm{g}^{-1}$. To validate the method, mercury in a certified reference material (CRM) MESS-3 was daily quantified and results were in the range of the certified value $\left(0.091 \pm 0.009 \mu \mathrm{g} \mathrm{g}^{-1}\right)$. 


\subsubsection{Dissolved phase characterization}

\subsubsection{Dissolved Organic Carbon (DOC)}

DOC concentrations were determined using the same TOC- $\mathrm{V}_{\mathrm{CSH}}$ analyzer, calibrated using potassium hydrogenophtalate (Shimadzu) standard solutions, with an accuracy of 0.02 $\mathrm{mgC} \mathrm{L}^{-1}$ (Louis et al., 2009). DOC analysis was validated using certified reference material (MISSIPPI-03, Canada); obtained values remained within the certified limits.

\subsubsection{Dissolved trace metals}

Total dissolved metal concentrations were determined by Differential Pulse Anodic Stripping Voltammetry $(\mathrm{Cd}, \mathrm{Cu}, \mathrm{Pb}$ and $\mathrm{Zn})$ and Differential Pulse Adsorptive Cathodic Stripping Voltammetry (Co and $\mathrm{Ni}$ ) using fully automated analytical procedures previously described (Louis et al., 2009; Omanović et al., 2006; Oursel et al., 2013).

Analysis were validated using certified "Nearshore Seawater Reference Material for Trace Metals" - CASS5 (NRC CNRC). All metal determinations remained within the certified limits.

\subsection{Modeling of the fate of particulate pollutant released at Cortiou during a flood event}

A 3D hydrodynamic (Pairaud et al., 2011) and sediment transport model (Verney et al., 2013) was implemented within the area to investigate the role of heavy rainfall events on the fate of contaminated particles, focusing on particulate $\mathrm{Pb}$ dynamics. Model functioning and input parameters are described in supplementary information SI-3. Briefly, the hydrodynamic part is based on the RHOMA configuration of the MARS3D ocean model developed by Ifremer (Pairaud et al., 2011) implemented from Rhone River to Cap Sicié (Fig. SI-3.1) with a $200 \mathrm{~m}$ horizontal resolution orthogonal grid and 30 vertical sigma levels. The sedimentary transport part was implemented from the SiAM3D model (Le Hir et al., 2011), with the sediment discretized in thin layers which are created or deleted based on net erosion/sedimentation at each time step. The model takes into account the various water sources from the city of Marseille: small urban rivers, storm water overflows and WWTP (Fig. 1 and SI-3.1). The flow from each input is defined using measured data provided by local authorities. Associated SPM concentrations were evaluated, depending on weather conditions, according to field measurements (Jany et al., 2012). Characteristics (proportion, settling velocity, pollutant content: Table SI-3.1) of 4 classes of particles were implemented 
in the model based on the results obtained in the present study (see part 3.3.1). Modelling of

particulate pollutant inputs and fate to the coastal zone was performed from the $12^{\text {th }}$ of September to the $28^{\text {th }}$ of October 2008, a period which included a strong rain event the $8^{\text {th }}$ of October 2008 with a cumulated rainfall of $41 \mathrm{~mm}$ (at "MARSEILLE-OBS" Météo-France rain gauge) inducing an outflow increase from 3 to $45 \mathrm{~m}^{3} \mathrm{~s}^{-1}$ at Cortiou (Fig. SI-3.2). The particulate $\mathrm{Pb}$ budget in the area was assessed for the Cortiou box $(43.18 \mathrm{~N} 5.35 \mathrm{E} / 43.22 \mathrm{~N}$ $5.45 \mathrm{E})$.

\section{Results and discussion}

\subsection{Mineralogical and elemental characteristics of flood deposits and baseflow suspended particles}

The mineral proportions determined by XRD in the 4 flood deposits varied from 6 to $11 \%$ for clay minerals, from 15 to $31 \%$ for quartz and from 50 to $69 \%$ for carbonates (calcite and dolomite). The calcareous pattern of these flood deposits are due to the nature of the river watersheds and so mainly composed of particles carried in rivers by rainwater after soil weathering.

Elemental composition of the samples used for the settling rate experiment are summarised in Table 1. Elemental compositions are here after compared (1) to the particles discharged by the Rhône River during flood events (flow $>1500 \mathrm{~m}^{3} \mathrm{~s}^{-1}$ ), considering that the Rhône River provides the most important discharge of particulate matter to the Mediterranean Sea (Cathalot et al., 2013; Ollivier et al., 2011), (2) to the Montreal effluents, as an example of large city effluent with high WWTP contribution (Gobeil et al., 2005), (3) to values obtained during baseflow periods at the Outlet2 (Oursel et al., 2013) and (4) to the upper continental crust (UCC) average values (Wedepohl, 1995).

Compositions of FDHuv, FDJar and FDOut2 samples were quite comparable, within a factor ranging from 0.5 to 2 , for most of the elements excepting $\mathrm{Pb}$ that was more than 10fold higher in the FDJar sample. The similar values between the two rivers reflect the similarities between their catchment areas. The similar values found between FDOut2 and rivers samples are likely due to the predominance at Outlet 2 of the river particles accordingly to higher river flow compared to WWTP effluent flow during flood events (cf. part 2.1.).

When compared to rivers values, the values obtained for the FDOut1 sample indicated a contamination with regard to most trace metals and metalloids. $\mathrm{Bi}, \mathrm{Hg}, \mathrm{Pb}$ and $\mathrm{Zn}$ values were 
for instance 16- to 30-fold higher when crustal elements (e.g. Al, Li, Rb, Ti) fell in the same range of value than on rivers. This contamination can be related to bypassing of non-treated wastewater in Outlet 1 during flood events (Fig. SI-4.1), permitting deposit of contaminantrich particles that would have normally been removed during the WWTP process by particles sedimentation (Buzier et al., 2011).

The POC content in the Huveaune and Jarret rivers (1.5-2.5\%) was in the same range of concentrations as in the Rhone River (Cathalot et al., 2013), but low when compared to FDOut2, FDOut1 and SPOut2 samples (2-, 7.4- and 7.9-fold less respectively), signature of high organic matter inputs by TWW, noticeable even in flood conditions.

Considering other elements, most values obtained for the Huveaune and Jarret rivers were slightly lower (in average 0.6 times lower) than in the Rhône River. The Al content, however, was around 6-fold lower than in the Rhône particles, indicating a lower proportion of the fine fraction that impacts most of trace metal contents (Roussiez et al., 2005). To better compare contamination status between rivers, it is therefore convenient to perform a normalization to Al content or other elements such as Fe, Ti, Th... (Larrose et al., 2010; Reimann and de Caritat, 2005; Vystavna et al., 2012). Here, Al-normalized values (data not shown) showed that $\mathrm{Ba}, \mathrm{Bi}, \mathrm{Co}, \mathrm{Cs}, \mathrm{Fe}, \mathrm{K}, \mathrm{Mn}, \mathrm{Na}, \mathrm{Rb}$, Ti and $\mathrm{V}$ contents in the FDHuv, FDJar and FDOut2 samples presented levels comparable to the Rhône River particles and to the UCC values, indicating a likely crustal origin. The $\mathrm{Sb}$ Al-normalized value was 2-foldhigher than the Rhône River particles value and 12-fold higher than the UCC value, indicating a significant contamination of the Huveaune and Jarret rivers. The $\mathrm{Ca}, \mathrm{Cd}, \mathrm{Cr}, \mathrm{Cu}, \mathrm{Mg}, \mathrm{Ni}, \mathrm{Pb}, \mathrm{Sr}$ and $\mathrm{Zn}$ Al-normalized values were 4- to 10-fold higher than the Rhône River particles values. These high values reflect the calcareous signature of Huveaune and Jarret watersheds for $\mathrm{Ca}, \mathrm{Mg}$ and $\mathrm{Sr}$ and a significant anthropogenic contamination for the other considered elements.

Regarding the FDOut1 samples, $\mathrm{Ba}, \mathrm{Co}, \mathrm{Cr}, \mathrm{Fe}, \mathrm{Hg}, \mathrm{Sb}$ values were from 4- to 15-fold higher and $\mathrm{Bi}, \mathrm{Cd}, \mathrm{Pb}, \mathrm{Zn}$ values respectively 47-, 24-, 240-, 126-fold higher than for the Rhône River particles, confirming the high contamination status of these samples likely due to a WWTP bypass.

Suspended particles collected during baseflow periods at Outlet 2 (SPOut2) were slightly less contaminated, but remaining in the range of variability of the baseflow periods values measured at Outlet 2 by Oursel et al. (2013). Consequently, elements content values of SPOut2 were close to those of FDOut2 excepting the POC and $\mathrm{Cu}$ contents which were respectively 4- and 3-fold higher. For most of elements, the SPOut2 values were in the same range of concentration than those observed in the Montreal WWTP effluent particles (Table 
1). Ag was considered as typical of urban input by Gobeil et al. (2005), recording $56 \mu \mathrm{g} \mathrm{g}^{-1}$ in the Montreal effluent. In the present study, Ag ranged from 0.62 to $32 \mu \mathrm{g} \mathrm{g}^{-1}$ at Outlet 2, where the WWTP signature is roughly divided by 2 during baseflow due to river inputs (Oursel et al.,2013), which confirms the significant input of this element by urban TWW.

Finally, for each sample the sum of $\mathrm{Ca}, \mathrm{Mg}$ and PIC contents was consistently close to the calcite and dolomite content obtained by XRD analysis.

\subsection{Data statistical analysis}

A statistical analysis (PCA, Principal Component Analysis) was applied to 116 samples issued from the present study (collected particles, settling experiment, marine sediments) and from Oursel et al. (2013) (baseflow suspended particles from Outlet 2). The two first factorial axes explained 50.60\% of the total variance (PC1: 36.95\%; PC2: 13.65\%) (Fig.SI-4.2). Additionally, as $\mathrm{Al}$ can be considered as a reference for terrigeneous particles, elements contents were plotted as a function of Al content (Fig. 2). These visualizations allowed identification of 4 groups of elements having similar behaviours.

The $1^{\text {st }}$ group was composed of $\mathrm{Al}$ and $\mathrm{Cs}, \mathrm{Li}, \mathrm{Rb}, \mathrm{Sr}$, Ti, elements typically terrigeneous having a good correlation with $\mathrm{Al}\left(\mathrm{R}^{2}>0.41\right)$; $\mathrm{Rb}$ is given in Fig. $2 \mathrm{~A}$ as an example. Suspended particles from baseflow periods had higher content for these elements than marine sediments; flood deposits were in between. Such patterns can be explained by a higher proportion of Al-rich particles in baseflow samples than in flood samples, while low values in marine sediments reflect dilution by calcitic autochthonous particles, as currently observed in coastal areas (Tessier et al., 2011). Cs, Ti and Rb were in the same order of concentrations than in UCC (Table 1), higher values for $\mathrm{Li}$ and $\mathrm{Sr}$ being related to the calcareous watersheds and soils (De Vos et al., 2006).

The $2^{\text {nd }}$ group was composed of $\mathrm{As}, \mathrm{Ba}, \mathrm{Fe}, \mathrm{Mo}, \mathrm{Pb}, \mathrm{Sb}, \mathrm{Zn}$, all uncorrelated with $\mathrm{Al}$ $\left(\mathrm{R}^{2}<0.06\right)$. Among these elements, $\mathrm{Ba}$ and $\mathrm{Fe}, \mathrm{Pb}$ and $\mathrm{Zn}$ presented a good correlation one with each other $\left(\mathrm{R}^{2}>0.69\right)$. This group is likely to reflect the affinity of elements for $\mathrm{Fe}$ oxides, regardless of terrigeneous origin because $\mathrm{Fe}$ (mainly as $\mathrm{FeCl}_{3}$ ) is currently used as flocculent in the WWTP process (Buzier et al., 2006; Buzier et al., 2011; Poon and Chu, 1999). As an example, points corresponding to low $\mathrm{Al}$ content associated to high $\mathrm{Fe}$ content in Fig. 2B correspond to FDOut1 and SPOut2 samples. Regarding As, Cancès et al. (2005) and Lenoble et al. (2012) shown that $\mathrm{As}^{\mathrm{V}}$ (the main fraction in oxic conditions) is dominantly 
sorbed/coprecipitated on/with Fe oxides, a minor fraction of $\mathrm{As}^{\mathrm{V}}$ remaining associated with clay minerals and/or $\mathrm{Al}$ hydroxides.

The $3^{\text {rd }}$ group, composed of $\mathrm{Ag}, \mathrm{Be}, \mathrm{Bi}, \mathrm{Cr}, \mathrm{Cu}, \mathrm{Co}, \mathrm{Cr}, \mathrm{Hg}, \mathrm{Mn}, \mathrm{Ni}, \mathrm{Sn}$ and $\mathrm{V}$ represents elements or compounds having a weak or moderate correlation with $\mathrm{Al}\left(0.07<\mathrm{R}^{2}<0.39\right)$. Among these elements, $\mathrm{Cr}$, $\mathrm{Co}$ and $\mathrm{Ni}$ presented high correlations one with each other ( $\mathrm{R}^{2}>0.87$ ), possible signature of common behaviour or origin, as cements manufacturing, (Frias and Sanchez de Rojas, 2002).

These two last groups can correspond to both contamination of river watershed and contamination by TWW and can be related to differential affinity with carrying phases.

A $4^{\text {th }}$ group was composed of $\mathrm{Ca}$ and PIC which had no correlation with $\mathrm{Al}$ but a good correlation one to each other. These elements signed the calcareous river watersheds or the marine calcitic particles (Fig.2C).

$\mathrm{Cd}$, located close to the center of the correlation circle, exhibited no significant correlation $\left(\mathrm{R}^{2}<0.04\right)$ with any other elements.

\subsection{Settling rates experiments}

\subsubsection{Settling rates and element distribution between particles}

The distribution of particles as a function of the settling rate is given in Fig.3. Additionally an experiment was done using FDOut2 sample sieved at $63 \mu \mathrm{m}$ and the same distribution of particles was obtained as a function of the settling rate (data not shown). For the 5 samples, 75 to $85 \%$ of the sample weight was comprised of particles whose settling rate was higher than $4 \mathrm{~mm} \mathrm{~s}^{-1}$, corresponding to particles which had an estimated diameter higher than $70 \mu \mathrm{m}$, and 0.2 to $7.6 \%$ of the sample weight was comprised of particles with settling rate was lower than $4 \mu \mathrm{m} \mathrm{s}^{-1}$, corresponding to particles which had an estimated diameter below $2.2 \mu \mathrm{m}$. Part of the large particles can result from flocculation processes in seawater (Manning et al., 2010).

The element contents in particles as a function of the settling rate showed four types of pattern. The $\mathrm{Ca}$ content was highest in high settling rate particles and decreased with decreasing settling rate (data not shown), Ca was thus mainly contained in large calcitic particles issued from erosion within the calcareous catchment area. The distribution of elements identified as typically terrigeneous ( $\mathrm{Al}, \mathrm{Cs}, \mathrm{Li}, \mathrm{Rb}, \mathrm{Sr}, \mathrm{Ti}, \mathrm{Tl})$ exhibited sigmoidal curves; $\mathrm{Al}$ is given as an example in Fig. 4A. Most metals ( $\mathrm{Ag}, \mathrm{As}, \mathrm{Bi}, \mathrm{Cd}, \mathrm{Cr}, \mathrm{Cu}, \mathrm{Fe}, \mathrm{Hg}$, $\mathrm{Mo}, \mathrm{Ni}, \mathrm{Pb}, \mathrm{V}, \mathrm{Zn}$ ) showed increasing contents with decreasing settling rates; $\mathrm{Cu}$ is given as 
an example in Fig. 4B. The fine fraction, mainly composed of clay minerals and oxihydroxides, is effectively known to concentrate metals by adsorption on high specific surface particles (Villaescusa-Celaya et al., 2000). Ba, Be, Co, K, Mg, Mn, Sb, Sn and U content distributions were roughly constant over the whole range of settling rates; $\mathrm{Sb}$ is given as an example in Fig. 4C. The POC distribution increased from large to fine particles for the SPOut2 sample but exhibited bell-shaped curve for other samples.

The element distribution asa function of the settling rate at $20^{\circ} \mathrm{C}$ was calculated for each element by multiplying the element content by the SPM concentration for each fraction; $\mathrm{Cu}$ is given as an example in Fig.SI-4.3. For a better understanding of the results, element distributions were reduced to between 4 size classes of particles based on the UddenWentworth sediment grain size scale, according to Leeder (1982) and Bainbridge et al. (2012): (1) sand particles (S), whose settling rate and diameter were higher than $3.3 \times 10^{-1} \mathrm{~cm}$ $\mathrm{s}^{-1}$ and $63 \mu \mathrm{m}$, respectively; (2) coarse silt particles (CS), whose settling rate were between $2.0 \times 10^{-2}$ and $3.3 \times 10^{-1} \mathrm{~cm} \mathrm{~s}^{-1}$ and diameter between 15.6 and $63 \mu \mathrm{m}$, respectively; (3) fine silt particles (FS), whose settling rate were between $1.3 \times 10^{-3}$ and $2.0 \times 10^{-2} \mathrm{~cm} \mathrm{~s}^{-1}$ and diameter between 3.9 and $15.6 \mu \mathrm{m}$, respectively; (4) fine fraction particles (FF), whose settling rate and diameter were lower than $1.3 \times 10^{-3} \mathrm{~cm} \mathrm{~s}^{-1}$ and $3.9 \mu \mathrm{m}$, respectively. Settling rate, SPM proportion and elements content of each fraction for the 5 studied samples are summarized in Table SI-5.1. The element distributions between each fraction are given in Fig.5 and Fig. SI4.4 , and classed by increasing contamination of the fine fraction.

FDJar, FDHuv, FDOut2 and SPOut2 samples exhibited similar distributions; FDOut2 is given as an example in Fig. 5A and for FDJar, FDHuv and SPOut2 samples graphs are plotted in Fig. SI-4.4A, B and C, respectively. Although the fine fraction was the most concentrated for most elements - and for all metals - the contribution of $\mathrm{S}$ and CS to the total contamination was the highest for all analysed elements because of the high contribution of the sand fraction to the sample weight. For all elements, more than $80 \%$ of the total load was contained in S plus CS. Contrarily, Bainbridge et al. (2012) observed in an Australian river flood plume that more than $70 \%$ of the total load was contained in FF plus FS. Here the relatively high metal load in coarse fractions could be due to flocculation of fine particles in seawater. The $\mathrm{Pb}, \mathrm{Cr}, \mathrm{Mo}, \mathrm{Bi}, \mathrm{Zn}$ and $\mathrm{Ni} F \mathrm{FF}$ contributions were higher in FDHuv than in FDJar although lower total contents in FDHuv than in FDJar (Table 1), which indicates different sources of contamination for the two rivers.

The FDOut 1 experiment exhibited a different distribution, with all elements a higher proportion of FF (Fig. 5B). 7.4\% of the total SPM had not yet sedimented after 5 days, most 
probably because of a higher proportion of organic particles issued from sewage bypassing.

Such particles are likely to remain in the surface layer of the plume and to be exported to the open sea with their contaminants load (more than $60 \%$ of the total $\mathrm{Pb}$ for instance). Under normal conditions, such particles would have probably been partly eliminated in the WWTP by flocculation after $\mathrm{FeCl}_{3}$ addition (Buzier et al., 2006).

\subsubsection{Settling rates and sedimentation at sea}

The fate of particles at sea was addressed by characterizing the marine surface sediments in front of Cortiou. Distribution of element contents in these sediments as a function of the distance from the outlet presented three main patterns (Fig. 6). (1) Ca and PIC contents decreased from the outlet to $400 \mathrm{~m}$ offshore then increased from 400 to $800 \mathrm{~m}$ offshore. This confirmed that the large calcitic particles were sedimented within $400 \mathrm{~m}$ from the outlet. The Ca content increase after $400 \mathrm{~m}$ is likely due to marine autochthonous calcite. (2) $\mathrm{Mg}$ and $\mathrm{Mn}$ exhibited constant values from 0 to $800 \mathrm{~m}$, which indicates a negligible or similar input from the suspended matter brought at the outlet and the marine organisms. (3) All other elements exhibited a significant increase from the outlet to at least $800 \mathrm{~m}$ offshore; $\mathrm{Pb}$ is plotted in Fig. 6 as an example. Such pattern is related to the fact that these elements are mainly contained in finer fractions that settle slowly with regard to the plume and seawater 3-D velocity field.

Additionally, trace elements concentrations in seafloor sediments were compared to the French action levels (N1 and N2) concerning dredged marine and estuarine sediment (JORF No. 184, 10-08-2000). Below the N1 level, the potential environmental impact of dredged sediment deposited onshore is considered neutral or negligible. Between levels N1 and N2, further investigation may be necessary. Above the N2 level, an impact on the environment is demonstrated. For trace metals, As and $\mathrm{Cr}$, were between the $\mathrm{N} 1$ and $\mathrm{N} 2$ levels and $\mathrm{Hg}, \mathrm{Cu}$, $\mathrm{Cd}, \mathrm{Pb}$ and $\mathrm{Zn}$ over-passed the $\mathrm{N} 2$ level by a factor 7, 2, 1.4, 1.2 and 1.4, respectively, in sediments sampled between 400 and $800 \mathrm{~m}$ from the outlet. Such urban impact on estuarine sediments was evidenced in other studies (Feng et al., 1998; Radakovitch et al., 2008).

\subsection{Evaluation of the fate of particulate $\mathrm{Pb}$ input to the coastal zone during a flood event by modeling}

The studied rain event ( $8^{\text {th }}$ of October 2008) discharged to the coastal zone $\sim 1.9 \mathrm{Mm}^{3}$ of water (accordingly to the measured flows), $\sim 650 \mathrm{t}$ of SPM and $\sim 170 \mathrm{~kg}$ of particulate $\mathrm{Pb}$ (values evaluated from the SPM vs. flow relationships (Table SI-3.1) and considering the 
proportion of the 4 fractions of particles and their $\mathrm{Pb}$ content (Table SI-5.1)). This last value, compared to the $\sim 300 \mathrm{~kg} \mathrm{y}^{-1}$ of particulate $\mathrm{Pb}$ discharged during dry weather at Cortiou (Jany et al., 2012; Oursel et al., 2013), confirmed the importance of pollutant inputs to the coastal zone from strong rain events in Mediterranean areas (Nicolau et al., 2012). Results on the fate of particulate $\mathrm{Pb}$ in the Cortiou box (Fig. SI-3.1) obtained with the 3D coupled RHOMA model are summarized in Table 2 and illustrated on Fig. 7 for deposition on seabed sediment of particulate $\mathrm{Pb}$ in CS, FS and FF fractions 4 days after the studied rain event. In comparison, similar maps simulated 1 day after the rain event are provided in Fig. SI-4.5 and clearly show the importance of local hydrodynamic, governed by offshore current and wind, on the fate of particles and associated pollutants. The S and CS fractions constituted $83 \%$ of the total SPM discharge which brought to the coastal zone $49 \%$ of the total $\mathrm{Pb}, \mathrm{S}$ being totally deposited on seabed sediment in vicinity of the outlet and CS in the Cortiou box after 4 days (Fig. 7A). FS particles (Fig. 7B) are partly trapped in sediments (23\%) or in the water column (11.5\%) and mainly exported offshore (65.5\%). Finally, FF represented only 14\% of the total SPM but $47 \%$ of the total $\mathrm{Pb}$ brought by this rain event. Accordingly to their weak settling rate both lowering their settling efficiency and enhancing influence of resuspension events (waves, hydrodynamic), these particles were totally exported offshore (99.5\%), only a small fraction remaining on seabed sediment (Fig. 7C). Results from this modelling also confirmed the observed $\mathrm{Pb}$ content distribution in surface sediments sampled from Cortiou outlet to $800 \mathrm{~m}$ offshore (Fig. 6). Indeed, considering the average $\mathrm{Pb}$ content of each of the 4 particles fraction and their respective fate in the studied area (Table 2), increases of measured $\mathrm{Pb}$ content (from 28 to $250 \mu \mathrm{g} \mathrm{g}^{-1}$ ) in surface sediments is most probably due to the deposition of S and CS, whereas the highest $\mathrm{Pb}$ content determined for FS and FF were not observed in surface sediments as they remained in the water column or were exported to the open sea. Consequently, if such urban inputs clearly affect the sediment quality locally, they also have a non-negligible influence on the water column due to the exportation of polluted particles offshore.

\subsection{Element release in seawater}

The percentage of metal released from the initial sample after $15 \mathrm{~min}, 1 \mathrm{~h}, 6 \mathrm{~h}, 24 \mathrm{~h}$ and 5 days of contact time with "clean" seawater was calculated. An example is plotted for $\mathrm{Cu}$ on Fig. SI-4.6, the percentages represent the $\mathrm{Cu}$ concentration in the solution divided by the $\mathrm{Cu}$ concentration in the corresponding initial sample (determined after acid and UV digestion). 
The metal release resulted from the balance between two opposite processes: (1) metal mobilization due to ionic exchange or degradation of organic complexes and (2) metal readsorption on existing or newly formed solid phase (Shulkin and Bogdanova, 2003), both processes depending on the nature of the solids, the particles size, the $\mathrm{pH}$ of the solution, the solid/liquid ratio (S/L) and the considered metal (Cantwell et al., 2008; Hatje et al., 2003).

$\mathrm{Cu}, \mathrm{Co}, \mathrm{Ni}$ and $\mathrm{Zn}$ exhibited similar release patterns, with a maximal release between 4 and 30\%, whereas $\mathrm{Cd}$ exhibited a higher release, between 11 and $100 \%$, and $\mathrm{Pb}$ a release lower than 1.1\%. Shulkin and Bogdanova (2003) observed similar $\mathrm{Cd}$ and $\mathrm{Pb}$ behavior when studying mobilization of riverine SPM in seawater. High release of $\mathrm{Cd}$, however, is well documented and corresponds to the formation of stable and soluble chlorocomplexes from particle-desorbed Cd (Dai and Martin, 1995; Waeles et al., 2008; Wang and Liu, 2003).

For all samples the metal release increased with contact time. Metal release was still occurring between 1 and 5 days, though with slower kinetics, indicating that the plume particles are able to release dissolved metals in the water column more than $24 \mathrm{~h}$ after discharge at sea. Particles can thus continue to release metals after their sedimentation or may release metals after surface sediment resuspension, e.g. during storms events. Similar kinetics were observed by Hatje et al. (2003) studying metal desorption in seawater from an estuarine sediment.

Samples FDHuv, FDJar and FDOut2 had similar behavior one to each other. The FDOut1 sample, although having higher metal concentrations than other samples, exhibited the lowest total release (11\% for $\mathrm{Cd}$ and less than $5 \%$ for other metals). As this sample was likely contaminated after WWTP by-passing, this would indicate a low metal lability from nontreated sewage particles. Compared to the present results, results of the 18/04/2012 campaign (by-pass of WWTP) published in Oursel et al. (2013) showed a higher metal released in the dissolved phase especially when samples were directly filtered on field. To the contrary, the SPOut2 samples that have a characteristic TWW signature exhibited the highest release for all metals, up to $100 \%$ for Cd. This indicates a higher metal lability from particles issued from the WWTP, likely due to changes in particles nature and reactivity through the treatment processes (Buzier et al., 2006). Oursel el al. (2013) published results of remobilization experiment designed to simulate mixing of outlet effluent with seawater during dry period. In the salinity gradient, the release of $\mathrm{Cd}$ was up to $100 \%$ after $6 \mathrm{~h}$ of mixing as it is found here. However, Oursel et al. (2013) observed that dissolved $\mathrm{Co}$ and Ni were adsorbed onto particles in the salinity gradient, showing a non-conservative behaviour. These differences are most 
probably related to the different $\mathrm{S} / \mathrm{L}$ ratio, as the lower is the ratio the more released is the metal.

\section{Concluding remarks}

Most studies dedicated to Mediterranean rivers input to the sea focused, on the one hand, on metal content in SPM and, on the other hand, on physical properties of suspended particles in estuaries. Here we investigated both chemical properties - metal content and metal release in the mixing zone - and physical properties - particles settling rate.

Metal and POC contents in river sediments were comparable to the values observed in other small coastal Mediterranean rivers and, at the TWW impacted outlet, comparable to the values observed in effluents of other large cities such as Montreal.

$\mathrm{Al}, \mathrm{Ca}, \mathrm{Cs}, \mathrm{Li}, \mathrm{Rb}, \mathrm{Sn}, \mathrm{Ti}$ and $\mathrm{V}$ were mainly of terrigenous origin while $\mathrm{Ag}, \mathrm{Ba}, \mathrm{Cd}, \mathrm{Cr}$, $\mathrm{Cu}, \mathrm{Hg}, \mathrm{Mg}, \mathrm{Mo}, \mathrm{Ni}, \mathrm{Pb}, \mathrm{POC}, \mathrm{Sb}$ and $\mathrm{Zn}$ were of anthropogenic origin as non-treated sewage, TWW or industrial waste. Many elements showed concentrations over the N2 French action level.

Although the fine fraction was the most concentrated for most elements (and for all metals) the contribution of the sand and the coarse silt fractions to the total contamination was the highest for all analysed elements.

A non-negligible part of metals could be exported to the open sea (e.g. more than $60 \%$ of total $\mathrm{Pb}$ ) due to non-settable contaminated particles (FDOut1 sample). This type of behaviour, due to non-treated urban particles, could also be observed along the Mediterranean coast especially in countries where WWTP are not set up.

Metal desorption kinetics in the mixing zone depended on the metal type and on the particles origin. Particles issued from the WWTP exhibited higher desorption and desorption rates than particles issued from non-treated sewage. Metal desorption still occur more than 24 $\mathrm{h}$ after mixing, indicating that the transfer of polluted fine particles to the open sea is most probably accompanied by a non-negligible pollutant release to the dissolved compartment, amplifying potential harmful effects to marine organisms.

In seafloor sediments, all metals exhibited a significant increase from the outlet to, at least, $800 \mathrm{~m}$ offshore indicating that the considered elements were partly contained in fractions that settles slowly with regard to the plume and seawater 3-D velocity field.

Implementation of settling particles characteristics in a 3D hydrodynamic and sediment transport model allowed evaluating the fate of particulate $\mathrm{Pb}$ in the studied area during a flood 
event, which confirmed the observed deposition of polluted particles in the coastal zone but also indicated a non-negligible export offshore of the finest particles.

\section{Acknowledgments}

The authors would like to thank all people who participated at sampling campaigns, for their help in samples preparation. The authors would also like to thank "IFREMER" (Dr. M. Zebracki, Dr. D. Cossa), "Météo-France" (Y. Bidet), "SERAM" (A. Queau), and "DEA" of Marseille city (Z. Djelalli) for access to the study site, material installation, flow and rainfall values, meteorological data at the Marseille observatory station ("GIRAC-PACA" project).The authors would also like to thank the team of Pr. H.-R. Pfeifer (CAM, Lausanne) for XRD analyses and the team of Pr. P. Doumenq (LCE, Aix-en-Provence) for sediments sampling campaign. We thank R. Verney (IFREMER, Brest) for his work in modeling sedimentary processes.

This collaborative work and B. Oursel Ph.D. were financially supported by the "ANR CES MARSECO" and the "GIRAC-PACA" projects (FUI, TPM, Région Provence Alpes Côte d'Azur); this study was part of the "MerMex-WP3-C3A" and international "IMBER" projects. The modeling work was funded and performed under the "METROC", "GIRACPACA", "EC2CO MASSILIA", "MerMex-WP3-C3A" and "PERSEUS FP7" projects.

\section{References}

Alliot, E., Younesa, W.A.N., Romano, J.C., Rebouillon, P., Massé, H., 2003. Biogeochemical impact of a dilution plume (Rhone River) on coastal sediments: comparison between a surface water survey (1996-2000) and sediment composition. Estuar. Coast. Shelf S. 57, 357-367.

Ammann, A.A., Rüttimann, T.B., Bürgi, F., 2000. Simultaneous determination of TOC and TNb in surface and wastewater by optimised high temperature catalytic combustion. Water Res. 34, 3573-3579.

Azimi, S., Rocher, V., Muller, M., Moilleron, R., Thevenot, D.R., 2005. Sources, distribution and variability of hydrocarbons and metals in atmospheric deposition in an urban area (Paris, France). Sci. Total Environ. 337, 223-239.

Bainbridge, Z.T., Wolanski, E., Álvarez-Romero, J.G., Lewis, S.E., Brodie, J.E., 2012. Fine sediment and nutrient dynamics related to particle size and floc formation in a Burdekin River flood plume, Australia. Mar. Pollut. Bull. 65, 236-248. 
Bay, S.M., Zeng, E.Y., Lorenson, T.D., Tran, K., Alexander, C., 2003. Temporal and spatial distributions of contaminants in sediments of Santa Monica Bay, California. Mar. Environ. Res. 56, 255-276.

Buzier, R., Tusseau-Vuillemin, M.-H., dit Meriadec, C.M., Rousselot, O., Mouchel, J.-M., 2006. Trace metal speciation and fluxes within a major French wastewater treatment plant: Impact of the successive treatments stages. Chemosphere 65, 2419-2426.

Buzier, R., Tusseau-Vuillemin, M.-H., Keirsbulck, M., Mouchel, J.-M., 2011. Inputs of total and labile trace metals from wastewater treatment plants effluents to the Seine River. Phys. Chem. Earth. Parts A/B/C 36, 500505.

Callahan, J., Dai, M., Chen, R.F., Li, X., Lu, Z., Huang, W., 2004. Distribution of dissolved organic matter in the Pearl River Estuary, China. Mar. Chem. 89, 211-224.

Cancès, B., Juillot, F., Morin, G., Laperche, V., Alvarez, L., Proux, O., Hazemann, J.L., Brown, G.E., Calas, G., 2005. XAS Evidence of As(V) Association with Iron Oxyhydroxides in a Contaminated Soil at a Former Arsenical Pesticide Processing Plant. Environ. Sci. Technol. 39, 9398-9405.

Cantwell, M.G., Burgess, R.M., King, J.W., 2008. Resuspension of contaminated field and formulated reference sediments Part I: Evaluation of metal release under controlled laboratory conditions. Chemosphere 73 , 1824-1831.

Cathalot, C., Rabouille, C., Tisnérat-Laborde, N., Toussaint, F., Kerhervé, P., Buscail, R., Loftis, K., Sun, M.Y., Tronczynski, J., Azoury, S., Lansard, B., Treignier, C., Pastor, L., Tesi, T., 2013. The fate of river organic carbon in coastal areas: a study in the Rhône River delta using multiple isotopic $(\delta 13 \mathrm{C}, \Delta 14 \mathrm{C})$ and organic tracers. Geochim. Cosmochim. Ac. 118, 33-55.

Cossa, D., Coquery, M., 2005. The Mediterranean mercury anomaly, ageochemical or a biological issue.Hdb. Env.Chem., vol. 5.Springer-Verlag, Heidelberg.

Cugier, P., Le Hir, P., 2002. Development of a 3D Hydrodynamic Model for Coastal Ecosystem Modeling. Application to the Plume of the Seine River (France). Estuar. Coast. Shelf S. 55, 673-695.

Dai, M.-H., Martin, J.-M., 1995. First data on trace metal level and behaviour in two major Arctic riverestuarine systems (Ob and Yenisey) and in the adjacent Kara Sea, Russia. Earth Planet. Sc. Lett. 131, $127-141$.

Dassenakis, M., Scoullos, M., Gaitis, A., 1997. Trace metals transport and behaviour in the Mediterranean estuary of Acheloos river. Mar. Pollut. Bull. 34, 103-111.

De Vos W., Tarvainen T., Salminen R., Reeder S., De Vivo B., Demetriades A., Pirc S., Batista M.J., Marsina K., Ottesen R.-T., O'Connor P.J., Bidovec M., Lima A., Siewers U., Smith B., Taylor H., Shaw R., Salpeteur I., Gregorauskiene V.1, Halamic J.1, Slaninka I., Lax K., Gravesen P., Birke M., Breward N., Ander E.L., Jordan G., Duris M., Klein P., Locutura J., Bel-lan A., Pasieczna A., Lis J., Mazreku A., Gilucis A., Heitzmann P., Klaver G., Petersell V., 2006. Geochemical Atlas of Europe. Part 2 - Interpretation of Geochemical Maps, Additional Tables, Figures, Maps, and Related Publications. http://weppi.gtk.fi/publ/foregsatlas/part2.php.

Di Leonardo, R., Vizzini, S., Bellanca, A., Mazzola, A., 2009. Sedimentary record of anthropogenic contaminants (trace metals and PAHs) and organic matter in a Mediterranean coastal area (Gulf of Palermo, Italy). J. Marine Syst. 78, 136-145. 
Dyer, K.R., Cornelisse, J., Dearnaley, M.P., Fennessy, M.J., Jones, S.E., Kappenberg, J., McCave, I.N.,

Pejrup, M., Puls, W., Van Leussen, W., Wolfstein, K., 1996. A comparison of in situ techniques for estuarine floc settling velocity measurements. J. Sea Res. 36, 15-29.

Eisma, D., Bale, A.J., Dearnaley, M.P., Fennessy, M.J., van Leussen, W., Maldiney, M.A., Pfeiffer, A., Wells, J.T., 1996. Intercomparison of in situ suspended matter (floc) size measurements. J. Sea Res. 36, 3-14.

Elbaz-Poulichet, F., Morley, N.H., Beckers, J.-M., Nomerange, P., 2001. Metal fluxes through the Strait of Gibraltar: the influence of the Tinto and Odiel rivers (SW Spain). Mar. Chem. 73, 193-213.

Elbaz-Poulichet, F., Garnier, J.-M., Guan, D.M., Martin, J.-M., Thomas, A.J., 1996. The Conservative Behaviour of Trace Metals $(\mathrm{Cd}, \mathrm{Cu}, \mathrm{Ni}$ and $\mathrm{Pb})$ and $\mathrm{As}$ in the Surface Plume of Stratified Estuaries: Example of the Rh ône River (France). Estuar. Coast. Shelf S. 42, 289-310.

Feng, H., Kirk Cochran, J., Lwiza, H., Brownawell, B.J., Hirschberg, D.J., 1998. Distribution of heavy metal and PCB contaminants in the sediments of an urban estuary: The Hudson River. Mar. Environ. Res. 45, 69-88.

Forstner, U., Wittmann, G.T.W., 1979. Metal Pollution in the aquatic environment. Springer-Verlag, New York.

Forstner, U., Patchineelum, S.R., 1980. Chemical associations of heavy metals in polluted sediments from the lower Rhine River. In: M.C. Kavanaugh and J.O. Leckie (Eds), particulates in Water. American chemical Society Advances in Chemistry Series 189, 177-193.

Frias, M., Sanchez de Rojas, M.I., 2002. Total and soluble chromium, nickel and cobalt content in the main materials used in the manufacturing of Spanish commercial cements. Cement Concrete Res. 32, 435-440.

Fugate, D., Chant, B., 2006. Aggregate settling velocity of combined sewage overflow. Mar. Pollut. Bull. 52, 427-432.

Gobeil, C., Rondeau, B., Beaudin, L., 2005. Contribution of Municipal Effluents to Metal Fluxes in the St. Lawrence River. Environ. Sci. Technol. 39, 456-464.

Hatje, V., Payne, T.E., Hill, D.M., McOrist, G., Birch, G.F., Szymczak, R., 2003. Kinetics of trace element uptake and release by particles in estuarine waters: effects of $\mathrm{pH}$, salinity, and particle loading. Environ. Int. 29, 619-629.

Heimbürger, L.-E., Cossa, D., Thibodeau, B., Khripounoff, A., Mas, V., Chiffoleau, J.-F., Schmidt, S., Migon, C., 2012. Natural and anthropogenic trace metals in sediments of the Ligurian Sea (Northwestern Mediterranean). Chem. Geol. 291,141-151.

Jany, C., Cossa D., Djelalli Z., Garnier C., Mounier S., Pairaud I. Sauzade D., Thouvenin B., Zebracki M. (2012). METROC : Evaluation des apports de contaminants chimiques de la métropole marseillaise au milieu marin, Report Ifremer RST.ODE/LER/PAC/12-02 - Agence de l'eau AERM\&C, 140 pp.

Jones, S.E., Jago, C.F., 1996. Determination of settling velocity in the Elbe estuary using quisset tubes. J. Sea Res. 36, 63-67.

JORF (Journal Officiel République Française), n¹84, 10-08-2000, ministère de l’aménagement du territoire et de l'environnement.

Larrose, A., Coynel, A., Schäfer, J., Blanc, G., Massé, L., Maneux, E., 2010. Assessing the current state of the Gironde Estuary by mapping priority contaminant distribution and risk potential in surface sediment. Appl. Geochem. 25, 1912-1923. 
Le Hir, P., Cayocca, F., Waeles, B., 2011. Dynamics of sand and mud mixtures : a multiprocess-based modeling strategy. Cont. ShelfRes., 31, 135-149.

Le Masson J., 1997. Mesures de pollution par temps de pluie à Marseille. Rapport SERAM.

Leeder, M.R., 1982. Sedimentology; process and product. Chapman and Hall, London.

Lenoble, V., Omanović, D., Garnier, C., Mounier, S., Đonlagić, N., Le Poupon, C., Pižeta, I., 2013. Distribution and chemical speciation of arsenic and heavy metals in highly contaminated waters used for health care purposes (Srebrenica, Bosnia and Herzegovina). Sci. Total Environ. 443, 420-428.

Lorrain, A., Savoye, N., Chauvaud, L., Paulet, Y.-M., Naulet, N., 2003. Decarbonation and preservation method for the analysis of organic $\mathrm{C}$ and $\mathrm{N}$ contents and stable isotope ratios of low-carbonated suspended particulate material. Anal. Chim. Acta 491, 125-133.

Louis, Y., Garnier, C., Lenoble, V., Mounier, S., Cukrov, N., Omanovic, D., Pizeta, I., 2009. Kinetic and equilibrium studies of copper-dissolved organic matter complexation in water column of the stratified Krka River estuary (Croatia). Mar. Chem. 114, 110-119.

Manning, A.J., Langston, W.J., Jonas, P.J.C., 2010. A review of sediment dynamics in the Severn Estuary: Influence of flocculation. Mar. Pollut. Bull. 61, 37-51.

Michel, P., Boutier, B., Chiffoleau, J.F., 2000. Net Fluxes of Dissolved Arsenic, Cadmium, Copper, Zinc, Nitrogen and Phosphorus from the Gironde Estuary (France): Seasonal Variations and Trends. Estuar. Coast. Shelf S. 51, 451-462.

Millward, G.E., Liu, Y.P., 2003. Modeling metal desorption kinetics in estuaries. The Science of The Total Environment 314-316, 613-623.

Millward, G.E., Sands, T.K., Jago, C.F., 1999. Particulate metals and their settling velocities in the Humber Estuary, UK. Mar. Chem. 68, 145-168.

Naudin, J.J., Cauwet, G., Chrétiennot-Dinet, M.J., Deniaux, B., Devenon, J.L., Pauc, H., 1997. River Discharge and Wind Influence Upon Particulate Transfer at the Land-Ocean Interaction: Case Study of the Rhone River Plume. Estuar. Coast. Shelf S. 45, 303-316.

Nicolau, R., Lucas, Y., Merdy, P., Raynaud, M., 2012. Base flow and stormwater net fluxes of carbon and trace metals to the Mediterranean sea by an urbanized small river. Water Res.

Ollivier, P., Radakovitch, O., Hamelin, B., 2011. Major and trace element partition and fluxes in the Rhône River. Chem. Geol. 285, 15-31.

Omanović D., Kwokal Z., Goodwin A., Lawrence A., Banks C.E., Compton R.G., S., K., 2006. Trace Metal Detection in Šibenik Bay, Croatia: Cadmium, Lead and Copper with Anodic Stripping Voltammetry and Manganese via Sonoelectrochemistry. A Case Study. Journal of the Iranian Chemical Society 3, 128-139.

Oursel, B., Garnier, C., Durrieu, G., Mounier, S., Omanović, D., Lucas, Y., 2013. Dynamics and fates of trace metals chronically input in a Mediterranean coastal zone impacted by a large urban area. Mar. Pollut. Bull. 69, 137-149.

Pairaud, I.L., Gatti, J., Bensoussan, N., Verney, R., Garreau, P., 2011. Hydrology and circulation in a coastal area off Marseille: Validation of a nested 3D model with observations. J. Marine Syst. 88, 20-33.

Phillips, J.M., Russell, M.A., Walling, D.E., 2000. Time-integrated sampling of fluvial suspended sediment: a simple methodology for small catchments. Hydrol. Process. 14, 2589-2602. 
Poon, C.S., Chu, C.W., 1999. The use of ferric chloride and anionic polymer in the chemically assisted primary sedimentation process. Chemosphere 39, 1573-1582.

Radakovitch, O., Roussiez, V., Ollivier, P., Ludwig, W., Grenz, C., Probst, J.-L., 2008. Input of particulate heavy metals from rivers and associated sedimentary deposits on the Gulf of Lion continental shelf. Estuar. Coast. Shelf S. 77, 285-295.

Reimann, C., de Caritat, P., 2005. Distinguishing between natural and anthropogenic sources for elements in the environment: regional geochemical surveys versus enrichment factors. Sci. Total Environ. 337, 91-107.

Rocha, L., Rodrigues, S.M., Lopes, I., Soares, A.M.V.M., Duarte, A.C., Pereira, E., 2011. The water-soluble fraction of potentially toxic elements in contaminated soils: Relationships between ecotoxicity, solubility and geochemical reactivity. Chemosphere 84, 1495-1505.

Roussiez, V., Ludwig, W., Probst, J.-L., Monaco, A., 2005. Background levels of heavy metals in surficial sediments of the Gulf of Lions (NW Mediterranean): An approach based on 133Cs normalization and lead isotope measurements. Environ. Pollut. 138, 167-177.

Shulkin, V.M., Bogdanova, N.N., 2003. Mobilization of metals from riverine suspended matter in seawater. Mar. Chem. 83, 157-167.

Statham, P.J., Leclercq, S., Hart, V., Batté, M., Auger, Y., Wartel, M., Cheftel, J., 1999. Dissolved and particulate trace metal fluxes through the central English Channel, and the influence of coastal gyres. Cont. Shelf. Res. 19, 2019-2040.

Tessier, E., Garnier, C., Mullot, J.-U., Lenoble, V., Arnaud, M., Raynaud, M., Mounier, S., 2011. Study of the spatial and historical distribution of sediment inorganic contamination in the Toulon bay (France). Mar. Pollut. Bull. 62, 2075-2086.

Thill, A., Moustier, S., Garnier, J.-M., Estournel, C., Naudin, J.-J., Bottero, J.-Y., 2001. Evolution of particle size and concentration in the Rhône river mixing zone:: influence of salt flocculation. Cont. Shelf. Res. 21, 2127 2140 .

Verney, R., Jany, C., Thouvenin, B., Pairaud, I., Vousdoukas, M., Pinazo, C., Ardhuin, F., Cann, P., 2013. Sediment transport in the bay of Marseille : role of extreme events. Proceedings of Coastal Dynamics'13, Arcachon, France, 1811-1822.

Villaescusa-Celaya, J.A., Gutiérrez-Galindo, E.A., Flores-Muñoz, G., 2000. Heavy metals in the fine fraction of coastal sediments from Baja California (Mexico) and California (USA). Environ. Pollut. 108, 453-462.

Vystavna, Y., Huneau, F., Schäfer, J., Motelica-Heino, M., Blanc, G., Larrose, A., Vergeles, Y., Dyadin, D., Le Coustumer, P., 2012. Distribution of trace elements in waters and sediments of the Seversky Donets transboundary watershed (Kharkiv region, Eastern Ukraine). Appl. Geochem. 27, 2077-2087.

Waeles, M., Riso, R.D., Le Corre, P., 2005. Seasonal variations of dissolved and particulate copper species in estuarine waters. Estuar. Coast. Shelf S. 62, 313-323.

Waeles, M., Riso, R.D., Le Corre, P., 2007. Distribution and seasonal changes of lead in an estuarine system affected by agricultural practices: The Penzé estuary, NW France. Estuar. Coast. Shelf S. 74, 570-578.

Waeles, M., Tanguy, V., Lespes, G., Riso, R.D., 2008. Behaviour of colloidal trace metals (Cu, $\mathrm{Pb}$ and $\mathrm{Cd})$ in estuarine waters: An approach using frontal ultrafiltration (UF) and stripping chronopotentiometric methods (SCP). Estuar. Coast. Shelf S. 80, 538-544. 
Wang, Z.-L., Liu, C.-Q., 2003. Distribution and partition behavior of heavy metals between dissolved and acid-soluble fractions along a salinity gradient in the Changjiang Estuary, eastern China. Chem. Geol. 202, 383396.

Weber, F.-A., Voegelin, A., Kretzschmar, R., 2009. Multi-metal contaminant dynamics in temporarily flooded soil under sulfate limitation. Geochim. Cosmochim. Ac. 73, 5513-5527.

Wedepohl, K.H., 1995. The composition of the continental crust. Geochim. Cosmochim. Ac. 59, 1217-1232.

Zwolsman, J.J.G., Van Eck, B.T.M., Van Der Weijden, C.H., 1997. Geochemistry of dissolved trace metals (cadmium, copper, zinc) in the Scheldt estuary, southwestern Netherlands: Impact of seasonal variability. Geochim. Cosmochim. Ac. 61, 1635-1652. 


\section{Figure caption}

Table 1: Elemental composition of the samples used for the settling rate experiment compared to the Rhône River (flow $>1500 \mathrm{~m}^{3} \mathrm{~s}^{-1}$, Cossa and Coquery, 2005; Ollivier et al., 2011; Cathalot et al., 2013), to the Montreal effluents (Gobeil et al., 2003), to the Marseille outlet under dry conditions (Oursel et al., 2013) and to the Upper Crust Continent (UCC, Wedepohl K.H., 1995).

Table 2: Calculated $\mathrm{Pb}$ fate in the coastal zone for the 4 particle fractions from 3D hydrodynamic and sediment transport modeling after a flood event $\left(8^{\text {th }}\right.$ of October 2008 5:00 AM to the $11^{\text {th }}$ of October 2008 5:00 PM)

Figure 1: Map of the studied site: the dotted area represents the urbanized zone of Marseille, (inset) position of the sediment sampling sites. Sampling points: O: outlet; Jar: Jarret River; Huv: Huveaune River; S1 to S12: surface sediment sampling points.

Figure 2: Variation of $\mathrm{Rb}(\mathrm{A}), \mathrm{Fe}(\mathrm{B})$ and $\mathrm{Ca}(\mathrm{C})$ contents as a function of $\mathrm{Al}$ content for dry period samples (open symbols), wet period samples (full symbols) and sediments $(+)$.

Figure 3: Variation of the percentage of particles for each class as a function of their settling rate and calculated diameter.

Figure 4: Distribution of $\mathrm{Al}(\mathrm{A}), \mathrm{Cu}(\mathrm{B})$ and $\mathrm{Sb}(\mathrm{C})$ contents for each class as a function of their settling rate.

Figure 5: Distribution of the percentage of element contents in each fraction for FDOut2 (A), and FDOut1 (B) samples.

Figure 6: Distribution of $\mathrm{Pb}, \mathrm{Ca}$ and $\mathrm{Mg}$ contents in surface marine sediments as a function of the distance from the Cortiou outlets. The dotted lines represent the mean values of $\mathrm{Pb}$ contents in the 4 particles fractions from 3D hydrodynamic and sediment transport modeling (Table 2).

Figure 7: Maps of particulate $\mathrm{Pb}$ deposition on seabed sediment for (A) coarse silt, (B) fine silt and (C) fine fraction (as percentage of the total particulate $\mathrm{Pb}$ discharged to the coastal zone for each fraction, expressed in $\log _{10}$ ) 4 days after the rain event of the $8^{\text {th }}$ of October 2008. 


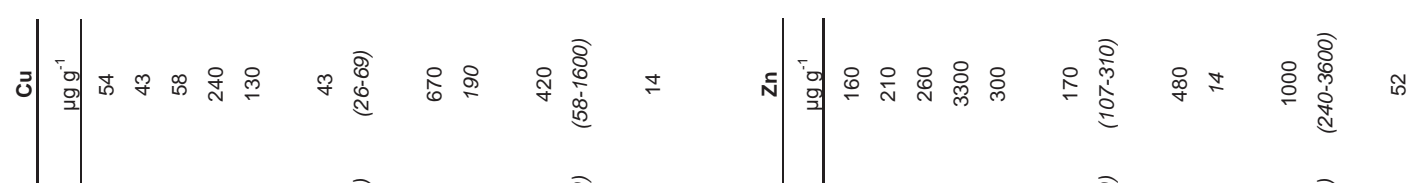

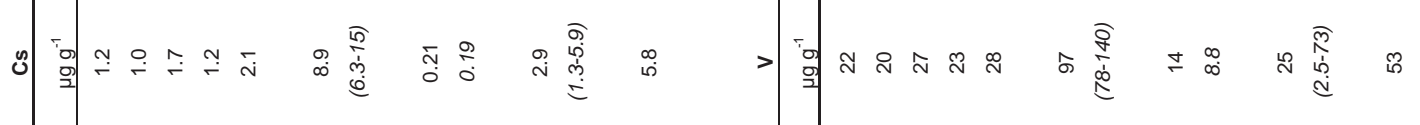

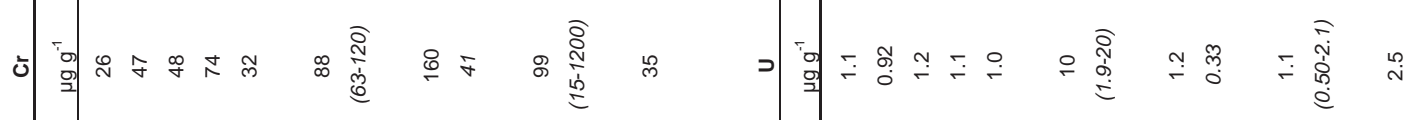

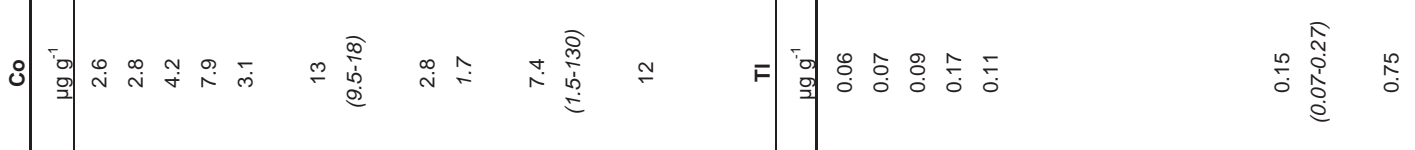

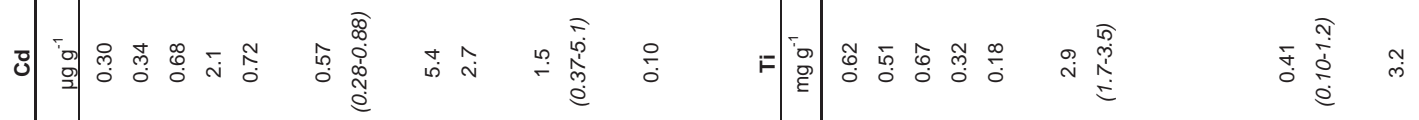

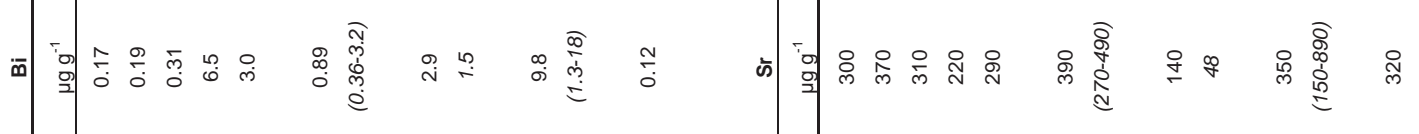

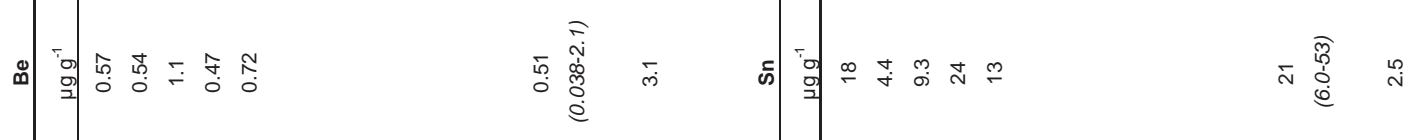

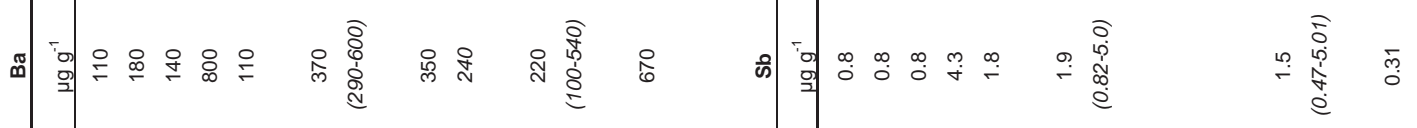

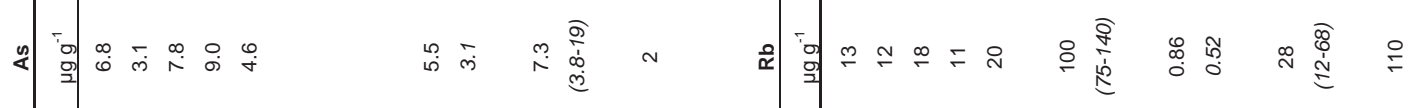

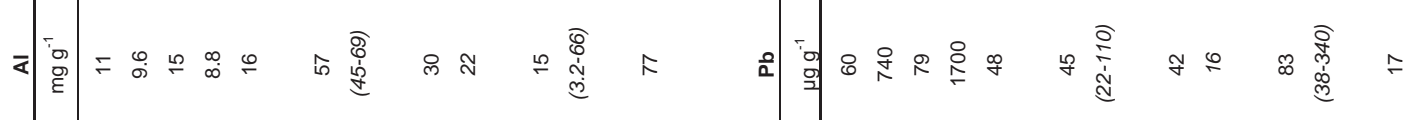

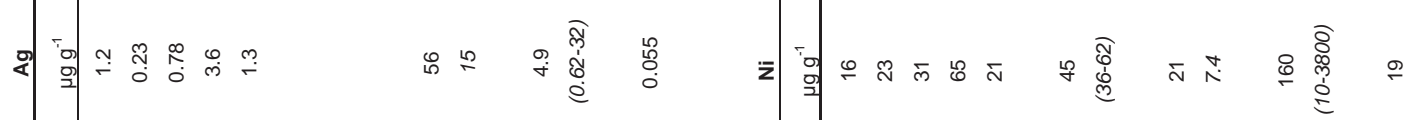

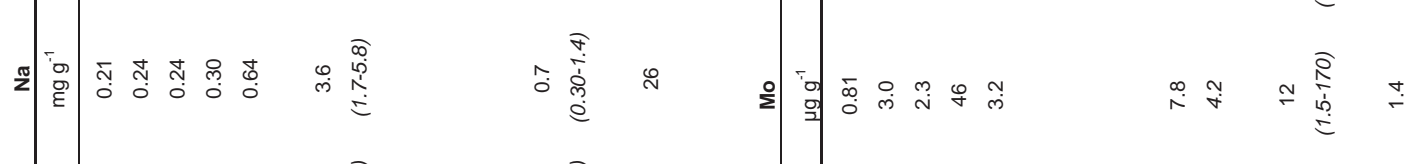

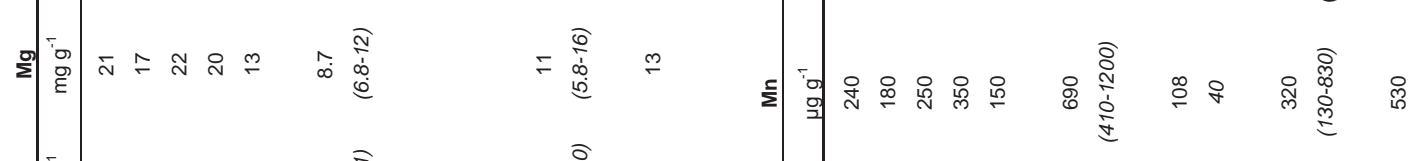

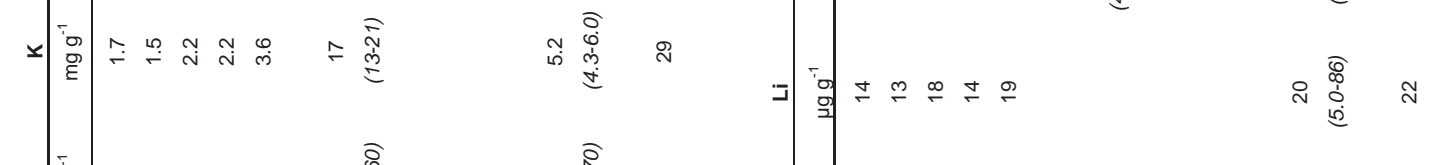

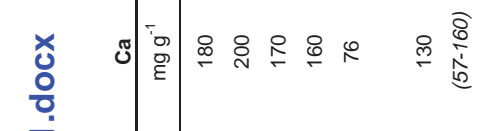
$\therefore \frac{0}{i} \quad$ i

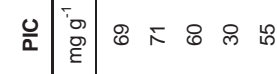
藏章

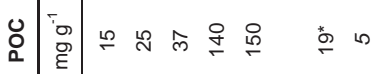
a

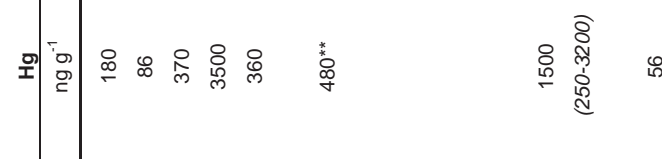
ᄂ|

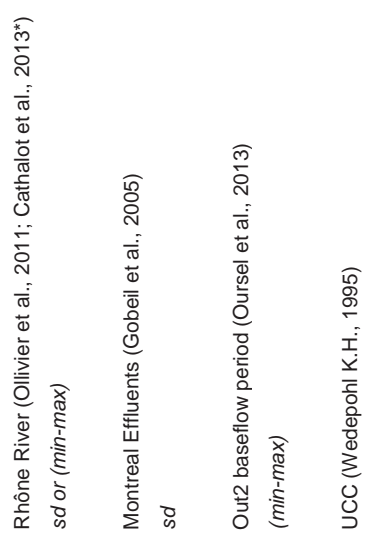

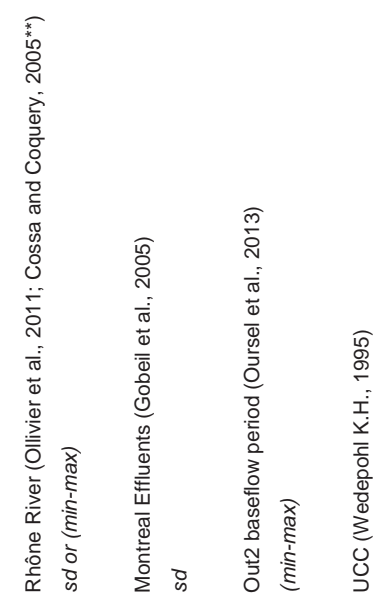


Table 2

Click here to download Table(s): Oursel et al Table 2.docx

\begin{tabular}{|c|cccc|}
\hline fraction & $\begin{array}{c}\mu \mathrm{g} \mathrm{g}^{-1} \\
\text { Pb content of } \\
\text { sedimented } \\
\text { particles }\end{array}$ & $\begin{array}{c}\% \\
\text { deposited } \\
\text { on seabed } \\
\text { sediment }\end{array}$ & $\begin{array}{c}\% \\
\text { trapped in } \\
\text { the water } \\
\text { column }\end{array}$ & $\begin{array}{c}\% \\
\text { exported } \\
\text { from the } \\
\text { box }\end{array}$ \\
\hline Sand & 140 & 100 & 0 & 0 \\
Coarse Silt & 210 & 99.7 & 0 & 0.3 \\
Fine Silt & 310 & 23 & 11.5 & 65.5 \\
Fine Fraction & 5900 & 0.4 & 0.1 & 99.5 \\
\hline
\end{tabular}




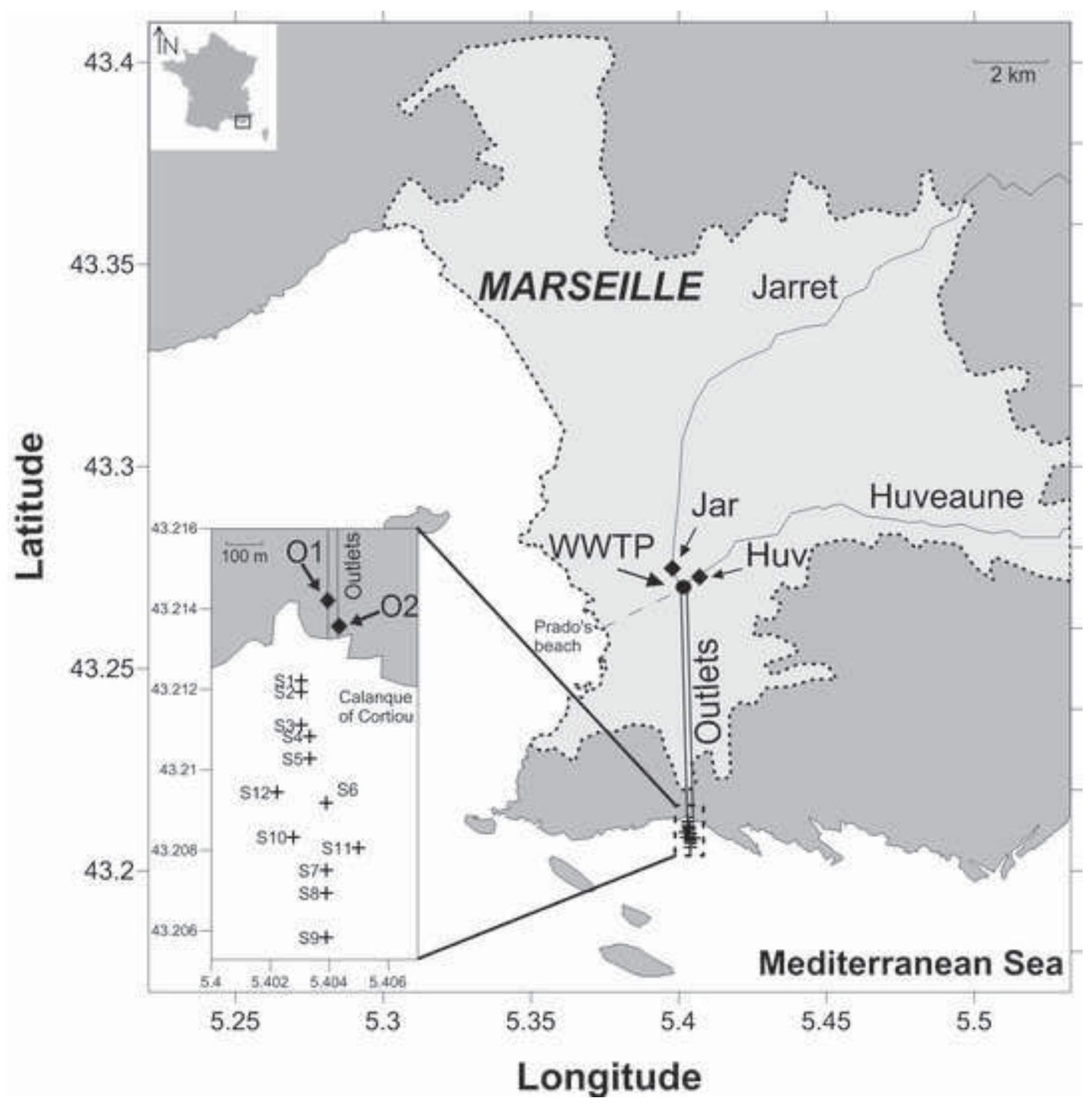


Figure 2
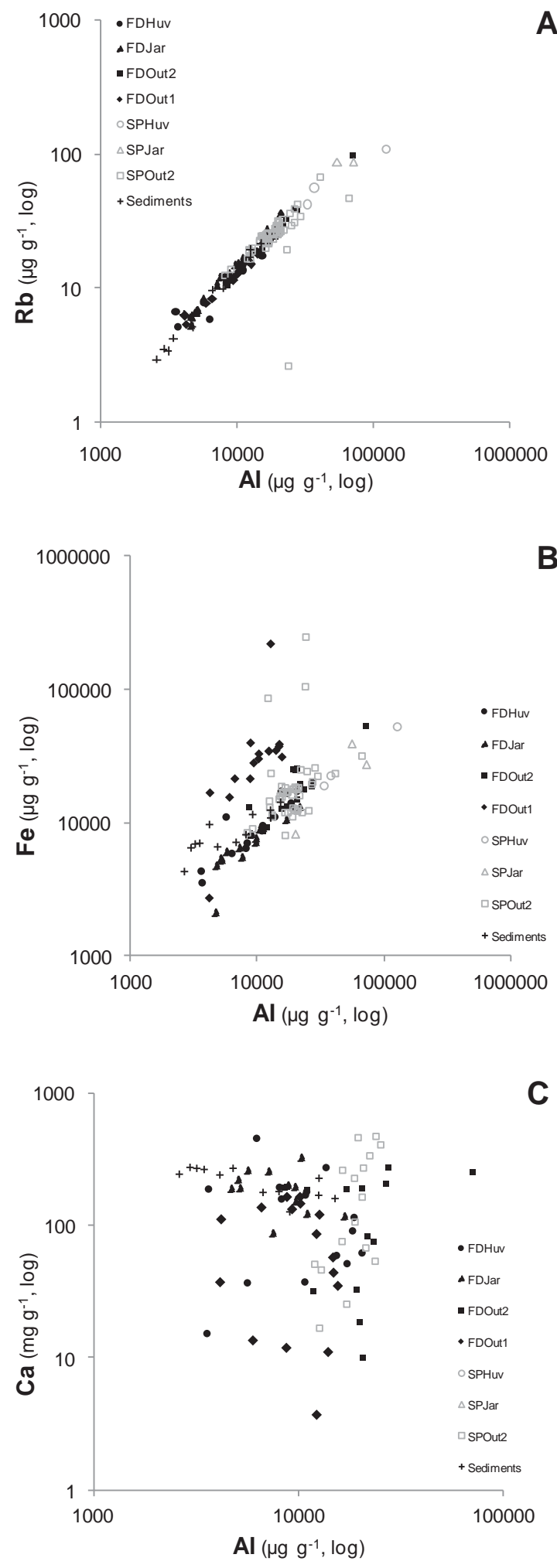

A

B

C 
Figure 3

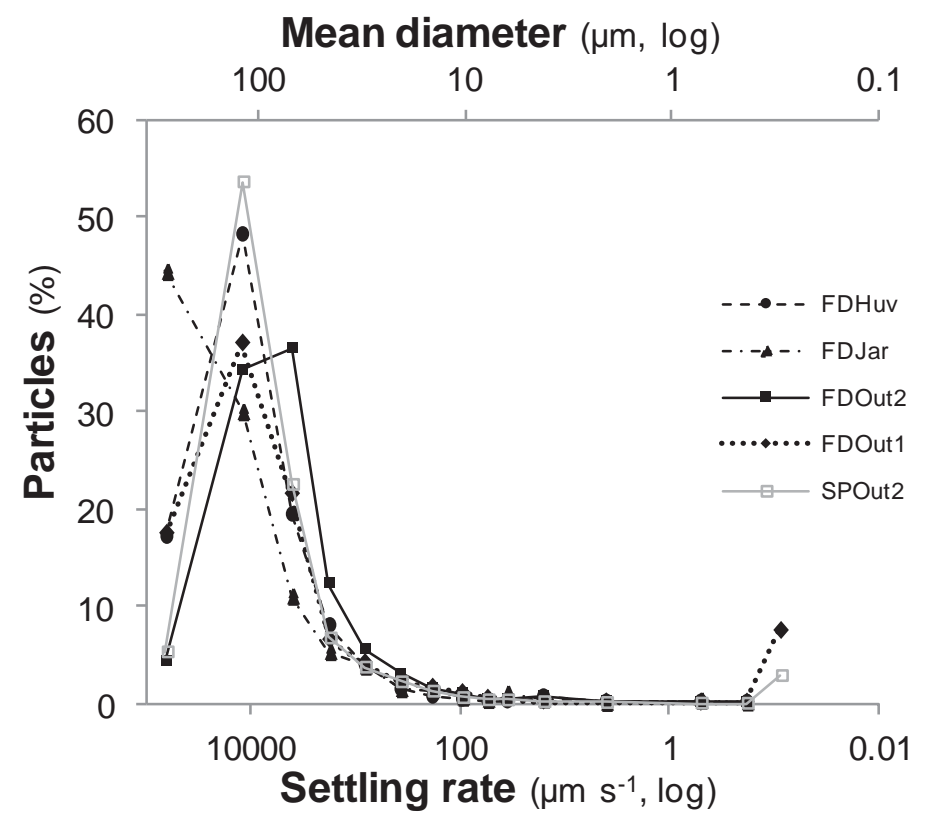




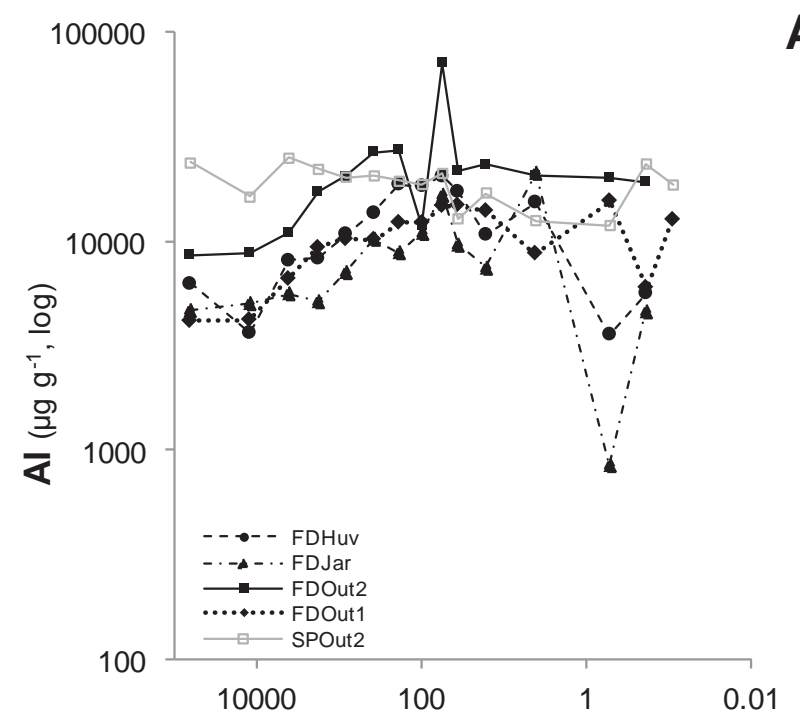

A

Settling rate $\left(\mu \mathrm{m} \mathrm{s}^{-1}, \log \right)$
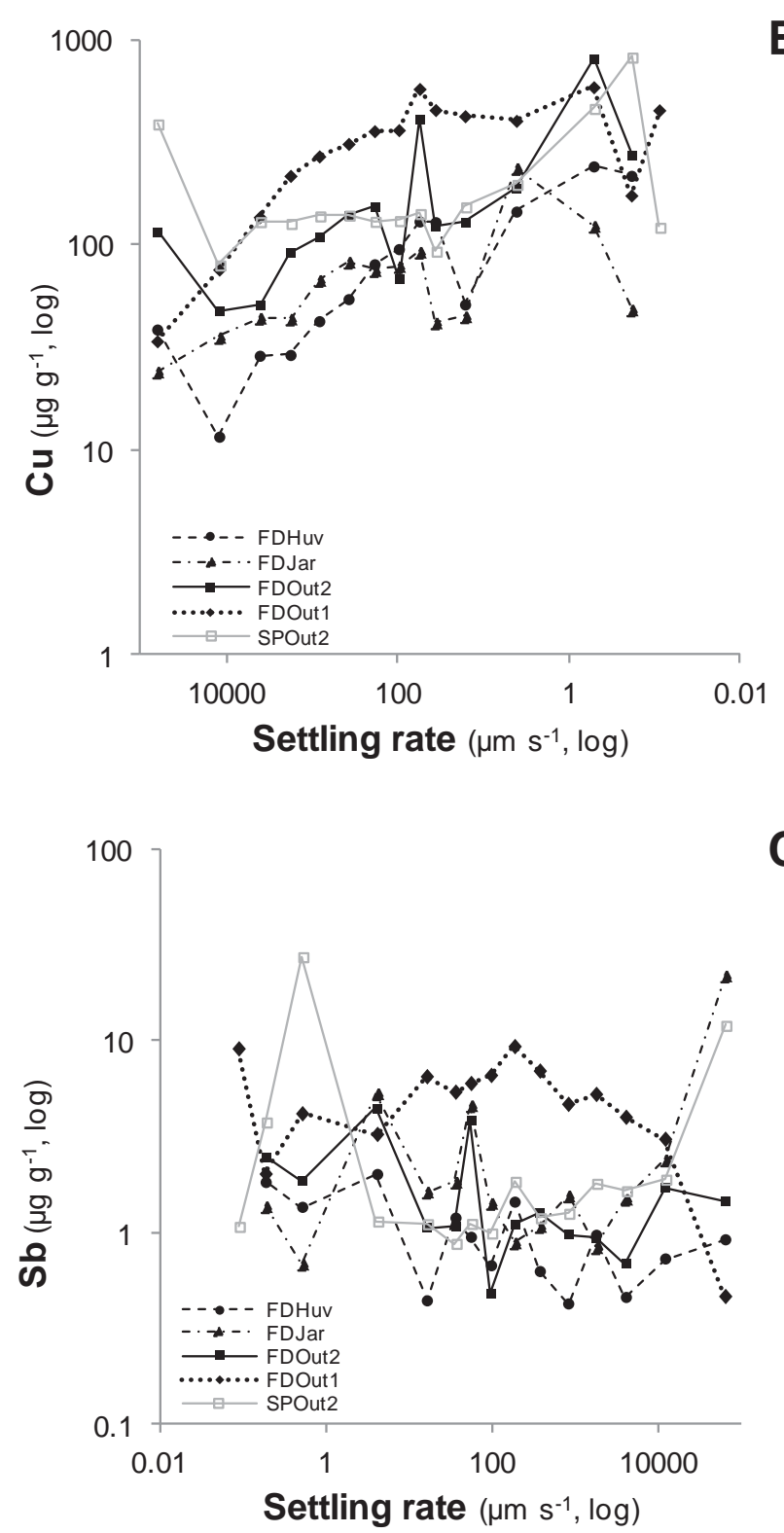

C 
Figure 5

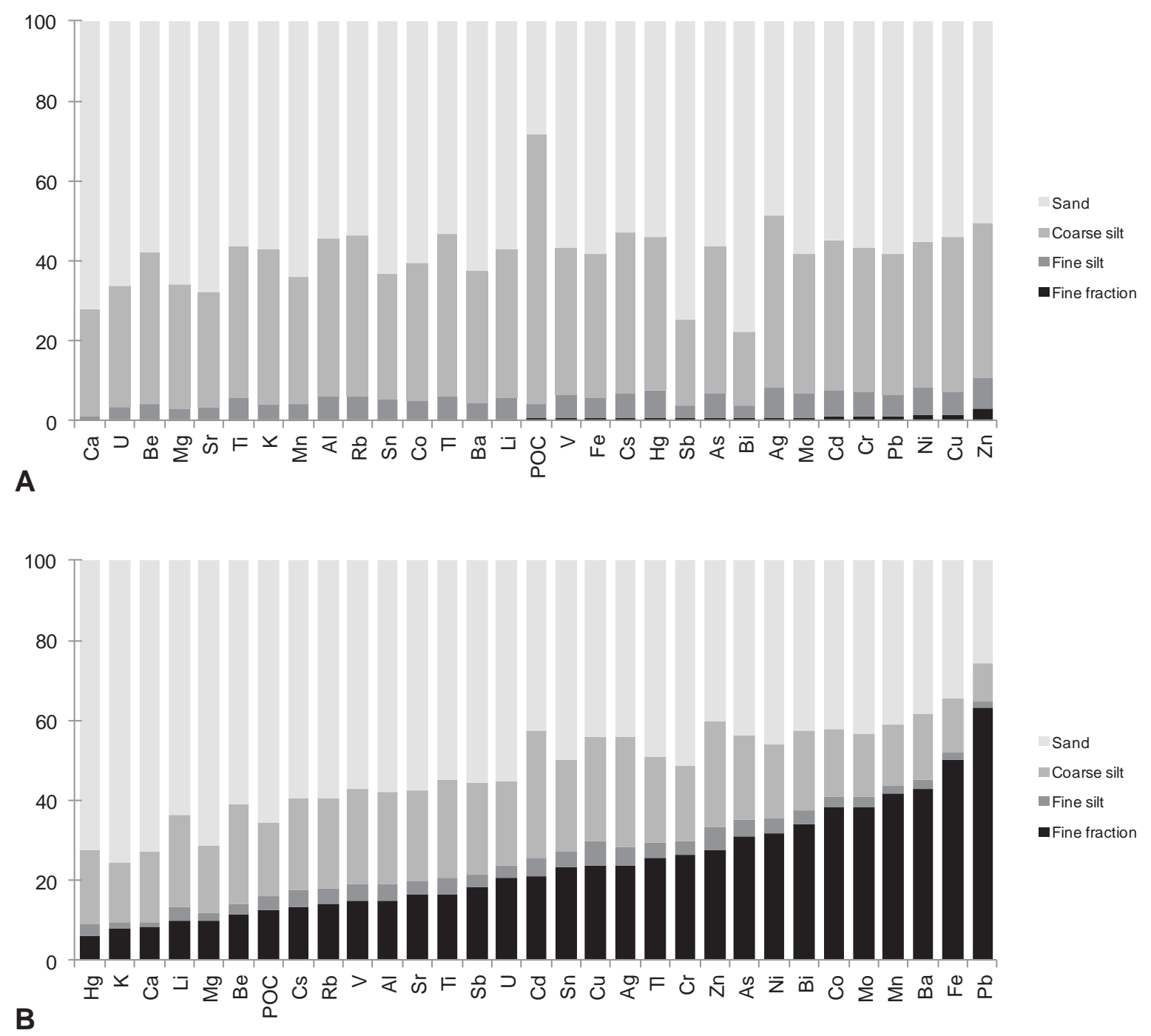


Figure 6

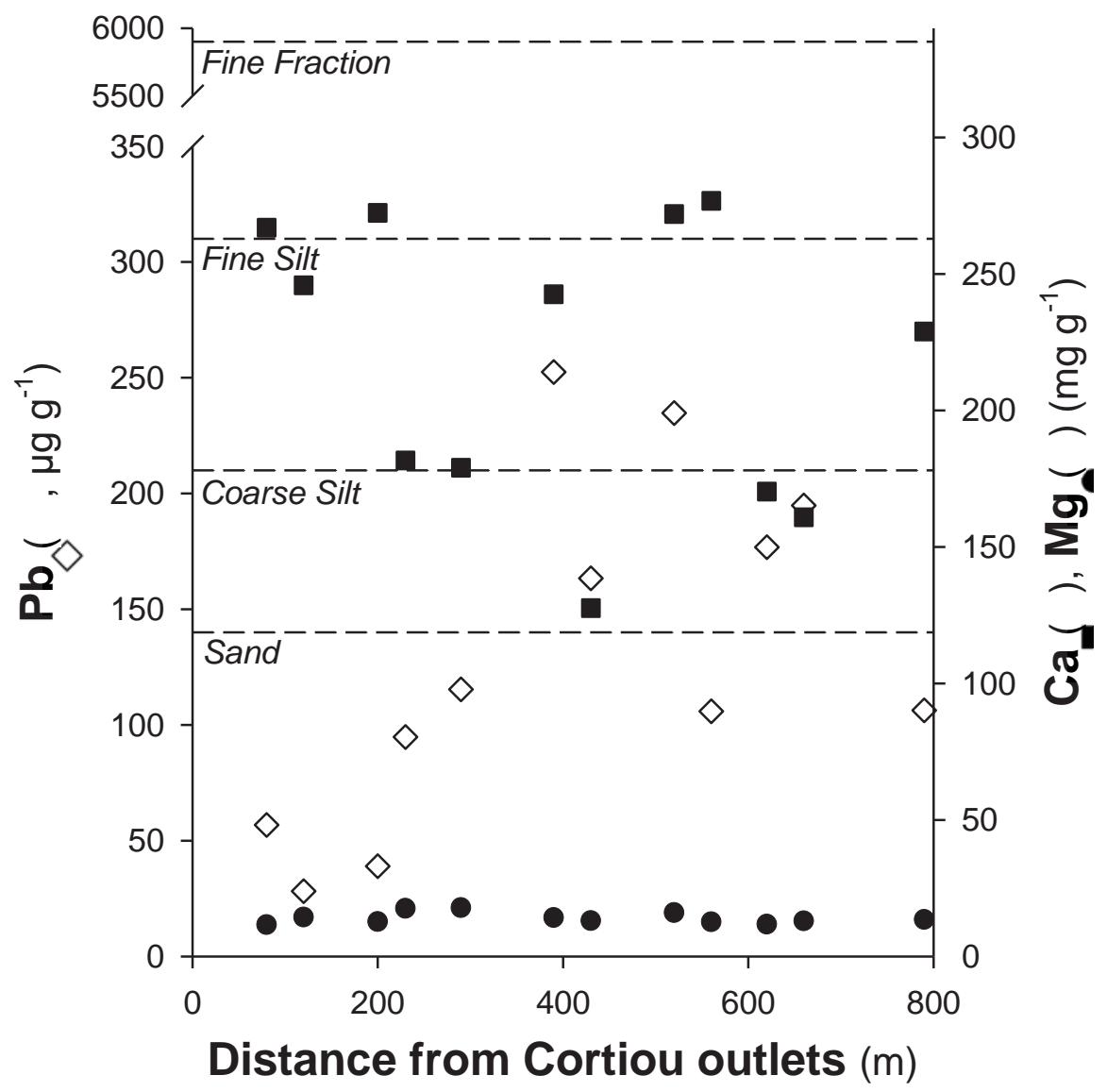



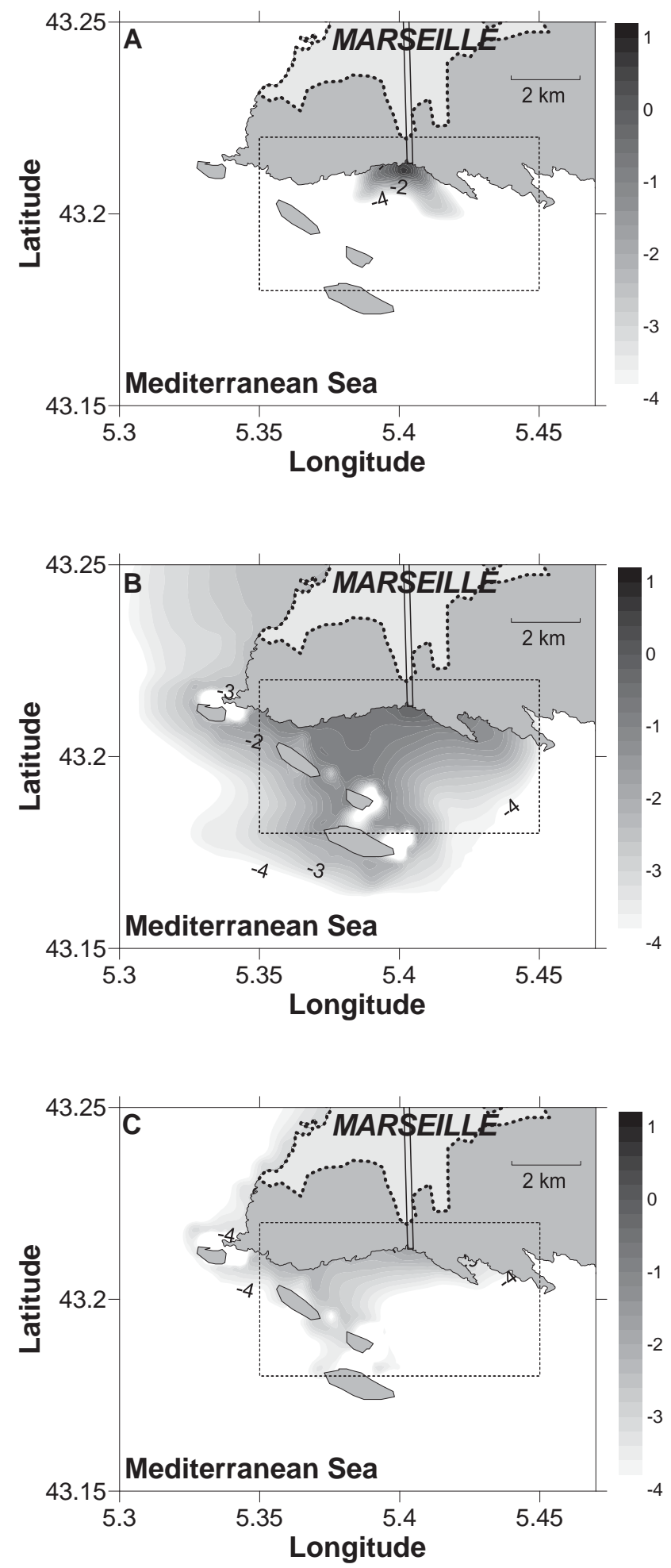
Click here to download Supplementary material for online publication only: Oursel et al SI corrected.docx 